Cahiers $d u$ MONDE RUSSE

\section{Cahiers du monde russe}

Russie - Empire russe - Union soviétique et États indépendants

45/3-4 | 2004

Varia

\title{
La mission diplomatique du père Antonio Possevino (s.j.) chez Ivan le Terrible en 1581-1582 et les premiers écrits jésuites sur la Russie moscovite à la fin du xvie siècle
}

\section{(2) OpenEdition}

Journals

Édition électronique

URL : https://journals.openedition.org/monderusse/8694

DOI : $10.4000 /$ monderusse. 8694

ISSN : $1777-5388$

Éditeur

Éditions de l'EHESS

Édition imprimée

Date de publication : 1 juillet 2004

Pagination : 407-440

ISBN : 2-7132-2009-2

ISSN : $1252-6576$

Référence électronique

STÉPHANE MUND, «La mission diplomatique du père Antonio Possevino (s.j.) chez Ivan le Terrible en 1581-1582 et les premiers écrits jésuites sur la Russie moscovite à la fin du xvie siècle ", Cahiers du monde russe [En ligne], 45/3-4 | 2004, mis en ligne le 01 janvier 2007, consulté le 04 septembre 2022. URL : http://journals.openedition.org/monderusse/8694 ; DOI : https://doi.org/10.4000/ monderusse.8694 
chercher : repérer : avancer

Cet article est disponible en ligne à l'adresse :

http://www.cairn.info/article.php?ID REVUE=CMR\&ID NUMPUBLIE=CMR 453\&ID ARTICLE=CMR 4530407

\section{La mission diplomatique du père Antonio Possevino (s.j.) chez Ivan le Terrible en 1581-1582 et les premiers écrits jésuites sur la Russie par STÉPHANE MUND}

\section{| Editions de I'EHESS | Cahiers du monde russe}

2004/3-4 - Vol 45

ISSN 1252-6576 | ISBN 2713220092 | pages 407 à 440

Pour citer cet article :

-MUND S., La mission diplomatique du père Antonio Possevino (s.j.) chez Ivan le Terrible en 1581-1582 et les premiers écrits jésuites sur la Russie moscovite à la fin du xvie siècle, Cahiers du monde russe 2004/3-4, Vol 45, p. 407-440.

Distribution électronique Cairn pour les Editions de l'EHESS.

(C) Editions de l'EHESS. Tous droits réservés pour tous pays.

La reproduction ou représentation de cet article, notamment par photocopie, n'est autorisée que dans les limites des conditions générales d'utilisation du site ou, le cas échéant, des conditions générales de la licence souscrite par votre établissement. Toute autre reproduction ou représentation, en tout ou partie, sous quelque forme et de quelque manière que ce soit, est interdite sauf accord préalable et écrit de l'éditeur, en dehors des cas prévus par la législation en vigueur en France. Il est précisé que son stockage dans une base de données est également interdit. 


\section{LA MISSION DIPLOMATIQUE DU PÈRE ANTONIO POSSEVINO (S.J.) CHEZ IVAN LE TERRIBLE EN 1581-1582 ET LES PREMIERS ÉCRITS JÉSUITES SUR LA RUSSIE MOSCOVITE À LA FIN DU XVI' SIÈCLE}

Lorsque le tsar Ivan IV le Terrible envoie le 6 septembre 1580 son émissaire Istoma Ševrigin à Rome pour demander au pape Grégoire XIII de servir de médiateur dans son conflit avec le roi de Pologne-Lituanie Étienne Bathory, il ne se doute pas que cette initiative inaugure une longue série de contacts entre son pays et l'Ordre des

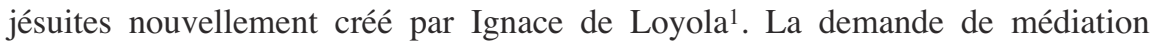
d'Ivan IV est en effet à l'origine de la mission diplomatique du père Antonio Possevino, qui a eu un impact important sur la connaissance de la Russie moscovite en Occident à la fin du XVI ${ }^{\mathrm{e}}$ siècle, comme je m'efforcerai de le montrer dans le présent article. Mais avant d'entrer dans le vif du sujet, il convient de replacer cette mission dans son contexte historique.

1. Ivan le Terrible (1547-†1584) est à cette époque en guerre contre le roi de Pologne-Lituanie Étienne Bathory $(1575-\uparrow 1586)$ qui cherche à lui reprendre le contrôle de la Livonie (actuelles Lettonie et Estonie), occupée depuis 1558 par les armées russes. Au cours de trois campagnes militaires victorieuses $(1579,1580$ et 1581$)$, Étienne Bathory reprend des territoires lituaniens (libération de la ville de Polock en 1579) occupés par les armées du tsar et entame la conquête du territoire russe (capture de la ville de Velikie Luki en 1580 et siège de la ville de Pskov en 1581). Devant l'ampleur de sa défaite, Ivan IV se résout à demander la médiation pontificale pour mettre fin au conflit, médiation qui est à l'origine de la mission jésuite en Russie. L'histoire des rapports entre les jésuites et la Russie aux XVI et XVII siècles a fait l'objet d'une excellente synthèse par J. S. Santich (O.S.B.), Missio Moscovitica; the role of the Jesuits in the Westernization of Russia, 1582-1689, New York, Peter Lang, 1995. 


\section{Les premières relations diplomatiques entre le Saint-Siège et les souverains de Moscou}

L'arrivée de Ševrigin à Rome le 24 février 1581 et son audience au Vatican deux jours plus tard, bien que sortant de l'ordinaire, ne constituent cependant pas un événement exceptionnel. Car ce n'est pas la première fois que le Saint-Siège accueille un envoyé de Moscou ${ }^{2}$. Depuis Sixte IV en effet, les souverains pontifes entretiennent des contacts diplomatiques intermittents avec la Russie, qui est à l'époque la nouvelle puissance ascendante de l'Europe orientale. Car ils caressent l'espoir de voir le grand-prince de Moscou, seul souverain orthodoxe non soumis au joug de la Porte ottomane, se rallier à leurs projets d'union des Églises et de croisade contre les Turcs. Les démarches pontificales n'ont cependant pas été couronnées de succès jusque-là, les souverains moscovites étant toujours restés sourds à leurs appels. Ainsi le grand-père d'Ivan IV, Ivan III, a été le premier à avoir noué des relations diplomatiques avec le Saint-Siège en 1471-1472 dans le cadre des négociations avec Sixte IV à propos de son mariage avec Zoé Paléologue. En lui accordant la main de l'héritière des empereurs byzantins élevée en exil à la Cour pontificale à Rome, le pape espérait rallier le grand-prince à ses projets ${ }^{3}$. Mais ceux-ci n'intéressaient guère Ivan III qui par son mariage recherchait plutôt un lien dynastique avec la dynastie impériale des Paléologues, susceptible de lui donner un surcroît de prestige et d'affermir par là-même sa suprématie sur les autres princes russes.

Son fils et successeur Vasilij III, qui est aussi le père d'Ivan IV, a poursuivi une politique semblable, à savoir obtenir habilement un maximum d'avantages du Saint-Siège sans pour autant entrer dans les desseins de ce dernier. En l'occurrence, il s'agissait pour lui d'établir de bons rapports diplomatiques avec la Papauté ainsi que d'autres États italiens dans le but de pouvoir recruter des techniciens italiens en Russie. En s'adressant à Grégoire XIII, Ivan IV ne fait par conséquent que poursuivre la politique de ses prédécesseurs. Dans sa demande de médiation adressée au pape, le tsar fait habilement allusion au fait que la Russie pourrait se joindre au projet de croisade pontificale après que la guerre avec la Pologne aura pris fin. Il espère ainsi l'amadouer et l'inciter à servir de médiateur dans son conflit avec Étienne Bathory. En revanche il se garde bien de faire la moindre allusion à une éventuelle union des Églises dont, à l'instar de ses prédécesseurs, il ne veut pas entendre parler. Si le pape et son entourage ne sont pas dupes des motifs intéressés de la démarche d'Ivan IV, ils voient cependant là une

2. Voir à ce sujet P. Pierling (S.J.), La Russie et le Saint-Siège, études diplomatiques, Paris, Librairie Plon, 5 vol., 1897-1912 ; 1, 1906, passim.

3. Zoé Paléologue (1503) est la nièce du dernier empereur byzantin Constantin XI tué lors de la prise de Constantinople par les Turcs le 29 mai 1453. Elle passe sa jeunesse à la Cour pontificale de Rome où son père Thomas Paléologue, le despote de Morée, s'est réfugié après la conquête ottomane de cet ancien territoire byzantin du Péloponèse. De son union avec le grand-prince de Moscou Ivan III (1462-†1505), naît en 1479 le futur Vasilij III $(1505-\dagger 1533)$. 
excellente occasion de réactiver la politique traditionnelle du Saint-Siège vis-àvis de $\mathrm{Moscou}^{4}$.

\section{La mission diplomatique de Possevino en Russie}

Répondant à la demande du tsar, Grégoire XIII décide d'envoyer en Russie une mission pontificale, dont la direction est confiée à Antonio Possevino, un jésuite italien à la forte personnalité qui a déjà eu l'occasion de rendre de grands services à la cause catholique en Piémont, en Savoie, en France et en Suède 5 . Possevino est chargé de remettre personnellement à Ivan IV une lettre de Grégoire XIII, datée du 15 mars 1581, dans laquelle le pape accepte de servir de médiateur dans le conflit l'opposant au roi de Pologne-Lituanie et encourage le tsar à accepter l'union des Églises sous l'égide de Rome et à participer au projet pontifical de croisade antiottomane. La mission qui incombe à Possevino est particulièrement délicate quand on connaît la force du sentiment anti-latin chez les Russes à l'époque. Le 27 mars 1581, jour de son départ, Possevino reçoit encore des mains du cardinal de Côme, Ptolomeo Galli, secrétaire des brefs « ad Principes », une instruction secrète où il est essentiellement question de l'union des Églises et de la façon dont l'envoyé

4. Le cardinal de Côme, secrétaire des brefs «ad Principes », écrit, le 4 mars 1581, à propos de la lettre d'Ivan IV adressée au pape le commentaire suivant : « Le style de la lettre est assez spécieux ; mais ceux qui savent, comme nous le savons tous, que cela ne provient pas des bonnes intentions, mais des bonnes défaites, [...] ceux-là ne sauraient se promettre quelque chose de bon de cette ambassade, d'autant plus que, quant à la religion, ne verbum quidem... ».

5. Avant de servir de médiateur pontifical auprès d'Ivan IV, Possevino a activement participé à la campagne de reconquête catholique des pays gagnés à la Réforme. En 1560, il a été envoyé en Piémont et en Savoie pour y combattre les calvinistes et les valdésiens. De 1563 à 1572, il est en France pour prêcher contre les huguenots et participer à la fondation de collèges jésuites . Entre 1577 et 1580 , il a été envoyé à deux reprises en Suède par Grégoire XIII dans le but de convaincre le roi Jean III Vasa, marié à une princesse Jagellon catholique, de se convertir au catholicisme et de restaurer l'ancienne foi dans son royaume. Bien que Possevino ne soit pas parvenu à changer le cours des choses, la façon dont il a mené la mission suédoise l'a fait remarquer au Saint-Siège. Au sujet de la vie de Possevino, voir l'étude déjà ancienne de L. A. Karttunen, Possevino, un diplomate pontifical au XVI siècle, Lausanne, 1908. La mission de Possevino en Russie a fait l'objet de nombreuses études parmi lesquelles on trouve : P. Pierling (S.J.), op. cit., 2, 1897 (1580-1596) ; O. Halecki, «Possevino's last statement on Polish-Russian relations », Orientalia Christiana Periodica, 1953, p. 261-302 ; S. Polčin (S.J.), Une tentative d'Union au XVI siècle : la mission religieuse du Père Antoine Possevin S.J. en Russie (15811582), Rome, Pont. Institutum orientalium studiorum, 1957, p. 1-59 (Orientalia Christiana Analecta, 150) ; M. Scaduto, « Ivan il Terribile e Antonio Possevino », Civiltà cattolica, 4, 1959, p. 292-296 ; W. Delius, Antonio Possevino S.J. und Ivan Groznyj. Ein Beitrag zur Geschichte der kirchlichen Union und der Gegenreformation des 16. Jahrhunderts, Stuttgart, Evangelisches Verlagswerk, 1962 (Beiheft zum Jahrbuch Kirche im Osten, 3) ; A. Kadič, « Križanič and Possevino - Missionaries to Muscovy », in T. Eekman, A. Kadič, eds., Juraj Križanič (161883) : Russophile and ecumenic visionary, Paris - La Haye, Mouton, 1976, p. 73-90 ; F. Guida, «Ivan il Terribile e Antonio Possevino : il difficile dialogo tra Cattolicesimo e Ortodossia », in S. W. Swiekosz-Lenart, ed., Le Origini e lo sviluppo della cristianità slavo-bizantina, Rome, 1992, p. 261-276 (Istituto Storico Italiano per il Medio Evo, Nuovi Studi Storici, 17); F. D. Liechtenhan, Les trois christianismes et la Russie. Les voyageurs occidentaux face à l'Église orthodoxe russe $X V^{e}-X V I I I^{e}$ siècle, Paris, CNRS Éditions, 2002, p. 48-52. 
pontifical devra s'acquitter de sa mission délicate en Russie 6 . Il lui est notamment demandé avec insistance de recueillir durant sa mission un maximum d'informations sur la Russie, son monarque, son peuple et bien entendu sur la religion orthodoxe pratiquée en Russie.

$\mathrm{Ne}$ connaissant pas le russe et n'ayant jamais mis les pieds en Russie, Possevino s'efforce au cours des quelques semaines précédant son départ de remédier à cette lacune par tous les moyens qu'il a à sa disposition. Ainsi il consulte les brefs des papes Léon X, Clément VII, Jules III et Pie V adressés à Vasilij III et à Ivan IV qui lui permettent de se mettre au courant des relations diplomatiques entre le SaintSiège et Moscou. La lecture des célèbres traités Libellus de legatione Basilii magni principis Moscoviæ de l'historien italien Paolo Giovio et Rerum Moscoviticarum Commentarii du diplomate impérial Sigismund von Herberstein lui permet d'avoir une bonne idée générale de la Russie ${ }^{7}$. Grégoire XIII lui passe, de la main à la main, la description de la Russie De Moscovia ad Clementem VII Pontificem Maximum écrite par le théologien hollandais Albertus Pighius pour Clément VII ${ }^{8}$. De même il

6. Instruction secrète analysée par S. Polčin (S.J.), op. cit., p. 4-7.

7. Herberstein $(* 1486-\dagger 1566)$ a fait une carrière de haut fonctionnaire à la Cour impériale et a servi comme diplomate les empereurs Maximilien I Ir, Charles Quint et Ferdinand. Envoyé à deux reprises pour négocier une paix entre la Pologne-Lituanie et la Russie en 1516-1518 et en 1526-1527, il écrit à la suite de ses séjours en Russie les Rerum Moscoviticarum Commentarii. Publié pour la première fois en latin à Vienne en 1549 , ce traité connaît un succès immédiat. Il est réédité, traduit en quatre langues et fait l'objet de nombreux emprunts dans divers ouvrages traitant de la Russie tout au long du XVI siècle. Paolo Giovio $(* 1486-\dagger 1552)$ est un prélat et un lettré de cour qui gravite dans les milieux pontificaux, où il s'attire successivement les faveurs des papes Léon X, Adrien VI et Clément VII. Il a acquis la célébrité dès le début de sa carrière en tant qu'historien. Moins connu que ses ouvrages d'histoire, son petit traité Libellus de legatione Basilii magni principis Moscoviæ, rédigé à partir des entretiens avec le diplomate russe Dmitrij Gerasimov et publié à Rome pour la première fois en 1525, a représenté une avancée significative dans la connaissance de la Russie en Occident avant la parution des Rerum Moscoviticarum Commentarii. Pour une étude de ces deux traités et de leur contribution fondamentale à la connaissance occidentale de la Russie, voir e.a. mon livre S. Mund, Orbis Russiarum. Genèse et développement de la représentation du monde « russe » en Occident à la Renaissance, Genève, Librairie Droz, 2003, p. 171-323, 357-437 (Travaux d'Humanisme et Renaissance, 382). Il existe une bibliographie récente des études consacrées à Herberstein : R. Frötschner, E. Maurer, « Herberstein-Bibliographie 1949-2002 », in F. Kämpfer, R. Frötschner, eds., 450 Jahre Sigismund von Herbersteins « Rerum Moscoviticarum Commentarii », 1549-1999. Jubiläumsvorträge, Wiesbaden, Harrassowitz, 2002, p. 399-408 (Schriften zur Geistesgeschichte des östlichen Europa, 24).

8. Théologien formé à l'université de Louvain, Albertus Pighius (*c.1490-†1542) est parti à Rome suivre son ancien professeur Adriaen Floriszoon devenu entre-temps le pape Adrien VI. Il passe ensuite le reste de sa carrière dans le sillage de la Papauté. Pighius compose son traité De Moscovia ad Clementem VII Pontificem Maximum pour le pape Clément VII à une époque où se nouent des contacts avec la Russie, contacts marqués notamment par la visite de Gerasimov déjà cité. Ce petit traité, publié pour la première fois à Rome en 1543, a comme objectif principal de montrer au pape combien un rapprochement avec les Russes pourrait être bénéfique pour le Saint-Siège face aux dangers de l'expansion ottomane et de la Réforme luthérienne. Ce traité est particulièrement intéressant pour Possevino, car il y est notamment question de l'union des Églises. Sans s'être jamais rendu en Russie, Pighius affirme que l'union des Églises est favorablement perçue par les Russes. Pour une étude du traité de Pighius, voir e.a. O. F. Kudrjavcev, ed., Rossija v pervoj polovine XVI v. : vzgljad iz Evropy (La Russie dans la première moitié du XVI siècle, vue d'Europe), Moscou, Russkij mir, 1997, p. 63-134 et S. Mund, « Le danger de l'expansion ottomane en Europe à l'origine de la redécouverte du monde russe 
reçoit le rapport de l'ambassadeur impérial Hans Cobenzl von Prosseg, envoyé par Maximilien II à Moscou en 1575, rapport qui a été remarqué au Vatican en raison de son caractère résolument optimiste à propos de l'union des Églises ${ }^{9}$. Possevino se procure des livres traitant des problèmes des Églises orientales qu'il étudie avec attention. Il consulte à Rome tous ceux qui sont censés être spécialistes de ces questions. Plus tard au cours de son voyage, il ne manque aucune occasion de se faire renseigner sur la Russie par ceux qui ont connu ce pays de leur propre expérience. De passage à Graz, il s'entretient longuement avec Hans Cobenzl von Prosseg. Il s'informe également auprès d'Istoma Ševrigin et de ses deux interprètes, Guillaume Popler et Francesco Pallavicino. Lors de son séjour en Pologne-Lituanie en route vers la Russie, Possevino rencontre plusieurs personnes qui lui fournissent des renseignements précieux au sujet de la Russie et de son tsar. Parmi eux, figure Giovanni Tedaldi, un marchand florentin, qui s'est rendu dix fois à Moscou, y a même séjourné pendant trois ans et a personnellement rencontré le tsar Ivan IV vers $1551^{10}$. En outre Possevino n'est pas seul pour accomplir sa mission délicate en Russie. En plus des indispensables interprètes, il a pour compagnons de voyage les pères jésuites Giovanni Paolo Campana et Stefan Drenocky ainsi que les frères novices Andrei Modestyn et Michele Morieno. Le choix de ces compagnons n'est pas innocent puisque trois d'entre eux au moins, à savoir Stefan Drenocky, Andrei Modestyn et Giovanni Paolo Campana, sont familiers du monde slave, les deux premiers par leurs origines respectives, croate et tchèque, le troisième parce qu'il a longtemps vécu en Bohême et en Moravie ${ }^{11}$.

Après un arrêt en cours de route, du 13 juin au 21 juillet, chez le roi Étienne Bathory, pour lui expliquer les objectifs et les enjeux de sa mission, Possevino et ses compagnons atteignent la frontière russe le 3 août 1581. Trois jours plus tard, le petit groupe, accompagné d'une escorte russe, atteint Smolensk, redoutable

en Occident ( $\mathrm{XV}^{\mathrm{e}}-\mathrm{XVI}^{\mathrm{e}}$ siècles) », Occident-Orient : aux origines du dialogue islamo-chrétien (XVI $-X I X^{e}$ s.). Actes de la IVe rencontre internationale (16-17 mai 2000), Zaghouan (Tunisie), FTERSI, 2002, p. 71-73 (Série 5 : Dialogue islamo-chrétien à l'époque de la Renaissance, 5).

9. Haut fonctionnaire de l'administration impériale, Hans Cobenzl (1598) a été envoyé par l'empereur Maximilien II de Habsbourg en Russie en 1575 pour demander le soutien d'Ivan IV à la candidature d'un archiduc Habsbourg sur le trône de Pologne-Lituanie, devenu vacant après la fuite précipitée du roi Henri de Valois pour la France en 1574. De son séjour chez le tsar, Cobenzl ramène un récit de voyage contenant une brève description de la Russie, dont plusieurs manuscrits sont parvenus jusqu'à nous aujourd'hui. Au sujet de Cobenzl et de son récit de voyage, voir e.a. B. Mitchell, R. Zguta, eds., « The sixteenth-century "Account of Muscovy" attributed to Don Felippo Prenestein », Russian History/Histoire Russe, 8, 1981, p. 390-412.

10. Au sujet de Tedaldi, voir P. Pierling (S.J.), op. cit., 2, p. 64-67.

11. Avant de se rendre en Russie pour y accompagner Possevino, Giovanni Paolo Campana $(* 1540-\uparrow 1592)$ a passé onze ans en Moravie et en Bohême, où il a enseigné dans les collèges et les noviciats jésuites. Sa connaissance du monde slave et de la langue tchèque a dû peser dans la décision de l'envoyer en Russie. Au sujet de la vie du père Campana, voir S. Bednarski, «Campani Jan Paweł (ok. 1546-1592) », Polski stownik biograficzny, Cracovie, 3, 1937, p. 196-197 et D. Caccamo, « Campana (Campani, Campanus), Giovanni Paolo », Dizionario biografico degli Italiani, Rome, 17, 1974, p. 346-349. Il n'existe pas à ma connaissance de biographies des trois autres jésuites. 
forteresse enlevée aux Lituaniens par les armées de Vasilij III en 1514. Conformément aux ordres d'Ivan IV, Possevino est brillamment reçu. Toutefois la réception de l'envoyé pontifical ne se déroule pas sans un incident diplomatique. En effet, l'évêque de la ville invite le lendemain Possevino à assister à une liturgie solennelle à la cathédrale. Il s'agit là d'une faveur particulière, faite à la demande expresse du tsar, dans la mesure où les Latins ne peuvent assister à un office orthodoxe et n'ont pas davantage le droit d'entrer dans les églises ${ }^{12}$. Possevino commence par décliner énergiquement cet honneur, de même qu'il refuse de baiser la main de l'évêque ${ }^{13}$. Il entend montrer par là qu'il ne peut rendre un signe d'hommage officiel à un prélat qui n'est pas en communion avec Rome. Il finit néanmoins par accepter d'assister à la liturgie pour obéir aux instructions pontificales lui enjoignant de profiter de son séjour en Russie pour y accumuler un maximum d'informations sur la foi des Russes. Quittant Smolensk le 8 août, le jésuite italien et sa suite sont conduits à Starica, petite ville située sur les bords de la haute Volga, où Ivan IV réside à l'époque afin d'être plus proche du théâtre des opérations militaires en Livonie.

Arrivés le 18 août, ils sont reçus solennellement le jour même par le tsar qui organise un dîner en leur honneur. Possevino et ses compagnons passent pratiquement un mois à Starica, du 18 août au 14 septembre, sans pouvoir sortir des murs de leur résidence qui est étroitement surveillée. Cet isolement que Possevino et Campana évoqueront plus tard dans leurs récits de voyage est une mesure adoptée par les souverains moscovites à l'égard des diplomates occidentaux pour des raisons de protocole mais aussi de méfiance vis-à-vis des envoyés étrangers perçus comme des espions potentiels ${ }^{14}$. À quatre reprises, Possevino est reçu en audience par Ivan IV et a de nombreux et longs débats avec les conseillers du tsar. Dès son premier discours, le jésuite italien tente d'aborder le problème de l'union des Églises avec Ivan IV. Il revient par la suite souvent sur cette question au cours de ses entretiens avec le tsar, mais il se heurte chaque fois au silence de ce dernier, bien décidé à ne pas évoquer le sujet avant la conclusion de la paix avec les Polonais ${ }^{15}$.

12. La hiérarchie religieuse russe n'est en effet pas favorable à l'entrée des « hérétiques latins » dans ses sanctuaires et ne l'accepte qu'à contrecœur, à la demande expresse du tsar ; ce dernier veut en effet que soient rendues aux envoyés pontificaux les mêmes marques de faveurs que celles accordées au Vatican à son représentant Sevrigin, qui a pu visiter les églises romaines et a assisté à un office liturgique à la basilique Saint-Pierre.

13. Campana raconte dans son récit que cet incident est né d'une confusion commise par l'interprète entre « obednja » qui signifie la messe et « obed » qui signifie le repas. Les jésuites croyant être invités à un repas découvrent avec étonnement qu'ils sont conviés à assister à l'office, d'où l'incident.

14. S. Mund, Orbis..., op. cit., p. 83-89.

15. Le sujet religieux est tellement délicat aux yeux d'Ivan IV, désireux de ne pas compromettre les négociations diplomatiques, qu'il a interdit aux Russes de l'escorte des jésuites d'en parler avec ces derniers et de garder à ce propos un silence absolu. Au cas où Possevino aborderait la question, le pristav (commissaire) chargé de l'accueillir et de l'accompagner a reçu du tsar l'ordre de lui répondre qu'il ne sait ni lire ni écrire et ensuite de se taire (Pamjatniki diplomatičeskikh snošenij, Saint-Pétersbourg, 10, 1871, col. 43). 
Le tsar accepte tout au plus de faire quelques concessions afin d'amadouer l'envoyé pontifical ; sur les instances de Possevino, il autorise désormais les envoyés du pape à traverser le territoire russe pour se rendre en Perse et accorde aux étrangers catholiques se rendant en Russie le droit d'être accompagnés de prêtres catholiques. De même la messe latine pourra être célébrée dans des établissements privés à condition que les sujets du tsar ne soient jamais admis à assister au culte. En revanche, Ivan IV refuse d'accorder une église et un cimetière pour les catholiques séjournant à Moscou.

Le 14 septembre, Possevino quitte Starica pour le théâtre des hostilités après avoir été officiellement chargé par Ivan IV d'engager les pourparlers avec Étienne Bathory. Avant son départ, il remet au père Drenocky, qui reste avec le frère Morieno auprès du tsar, des instructions détaillées sur l'attitude à adopter durant son séjour prolongé. Quant au père Campana, parti en même temps que Possevino, il est envoyé par ce dernier à Rome afin d'y rendre compte des premiers résultats de la mission pontificale ${ }^{16}$. Du 14 septembre 1581 au 23 janvier 1582, Possevino séjourne dans la région de Novgorod et de Pskov et joue le rôle de médiateur dans les négociations longues et difficiles entre les délégués russes et leurs collègues polonais-lituaniens. Le 15 janvier enfin, une trêve de dix ans est signée entre les parties belligérantes dans le petit village de Jam Zapolskij grâce à l'habileté et à la ténacité de Possevino ${ }^{17}$. Le 23 janvier 1582, le jésuite italien part pour Moscou afin d'y rencontrer le tsar et y retrouver ses compagnons restés en Russie. En chemin, il s'arrête deux jours à Novgorod où il est accueilli par l'archevêque de la ville qui l'invite à assister à la liturgie dans la célèbre cathédrale Sainte-Sophie. Comme à Smolensk, Possevino décline obstinément cet honneur, affirmant qu'il ne peut participer à un office célébré par un prélat qui n'est pas en communion avec l'Église romaine. Il manifeste cependant le désir de visiter la cathédrale et de contempler en particulier les tombeaux des saints russes qui y sont enterrés. Cette visite est l'objet d'un nouvel incident diplomatique entre l'archevêque de Novgorod et Possevino qui affirment chacun haut et fort être membres de la seule vraie Église et s'accusent mutuellement d'hérésie.

Le 13 février 1582, l'envoyé pontifical arrive à Moscou, officiellement afin de rendre compte des résultats de sa médiation, mais aussi pour évoquer avec Ivan IV la question épineuse de l'union des Églises et son corollaire, la participation russe à la croisade anti-ottomane du pape. Possevino obtient non sans mal de pouvoir débattre de l'union des Églises avec lui au cours d'un colloque tenu au Kremlin le

16. Campana ne rentrera finalement pas à Rome rendre compte de sa mission chez Ivan IV, car il a entre-temps été nommé Provincial de Pologne. Au cours des années suivantes, il joue un rôle actif dans l'expansion de l'Ordre des jésuites non seulement en Pologne-Lituanie et dans les territoires reconquis de la Livonie, mais également en Transylvanie, pays d'origine du roi Étienne Bathory, son protecteur.

17. Par la conclusion de cette trêve, Ivan IV renonce à toutes ses conquêtes en Livonie et restitue les territoires lituaniens (Polock) conquis durant la Guerre de Livonie en échange de la restitution des territoires russes conquis par les armées d'Étienne Bathory en 1580-1581. 
21 février en présence des boyards et des principaux dignitaires de la Cour ${ }^{18}$. Le débat entre l'envoyé du pape et le tsar tourne cependant vite à l'aigre tant les positions des deux interlocuteurs sont irréconciliables et grande l'aversion d'Ivan IV à l'égard de l'union religieuse avec Rome. Un moment forcé dans ses retranchements par le redoutable dialecticien qu'est Possevino, Ivan IV se met en colère et crée même un incident diplomatique en lançant un propos insultant à l'égard du pape ${ }^{19}$. Deux autres rencontres entre Possevino et Ivan IV, les 23 février et 4 mars, se révèlent également infructueuses. Le jésuite italien à son tour fait un affront au tsar en déclinant son invitation à assister à l'office du premier dimanche de carême dans la cathédrale de la Dormition du Kremlin ${ }^{20}$. Comme à Smolensk et à Novgorod, l'envoyé du pape a encore une fois décliné ce qui était considéré aux yeux des Russes comme un honneur exceptionnel, arguant du fait qu'il ne voulait pas cautionner par sa présence l'Église russe «schismatique ». Possevino, accompagné de sa suite, quitte Moscou le 14 mars 1582. S'il a réussi par son habileté diplomatique à mettre fin à la longue Guerre de Livonie, il n'est en revanche pas parvenu à obtenir l'accord d'Ivan IV au sujet de l'union des Églises et un engagement ferme de celui-ci à propos de la participation russe à l'alliance anti-ottomane.

Le séjour de Possevino et de ses compagnons en Russie ne s'est pas déroulé sans incidents avec les autorités, comme l'ont déjà montré les rencontres avec la hiérarchie orthodoxe de Smolensk et de Novgorod. Il convient encore d'ajouter le refus du jésuite italien de participer aux libations en alcool qui atteste également son incompréhension à l'égard des usages du cérémonial de la cour : il décline ce qui est en réalité une faveur octroyée par les Russes à un hôte de marque. De même il manifeste un certain agacement face à l'énumération répétée de tous les titres du tsar, conforme au cérémonial compliqué de la cour moscovite : il la perçoit comme un signe de l'orgueil démesuré des Russes, auquel il répond en déclinant à son tour la liste des titres du pape. L'incompréhension caractérise également l'autre camp : les Russes recevant avec beaucoup de pompe l'ambassade pontificale relèvent avec condescendance la pauvreté de la tenue des jésuites. Cette remarque désobligeante leur vaut une réplique cinglante de la part de Possevino qui s'empresse d'expliquer que les jésuites sont pauvres parce que leurs richesses sont consacrées aux églises.

18. Il existe deux versions du colloque entre Possevino et Ivan IV, l'une rédigée par un d'jak (secrétaire) pour les archives du tsar, l'autre rédigée par Possevino à l'intention du pape et publiée en 1586 dans son traité Moscovia. D'après Polčin qui les a analysées (op. cit., p. 3652), les deux rédactions ne se contredisent pas fondamentalement à l'exception de certains passages. Elles se complètent plutôt.

19. Ivan IV aurait dit à Possevino : « Sache que le Pontife romain n'est pas un pasteur, mais un loup ». Face à cette insulte, Possevino aurait gardé son sang-froid, ce qui aurait permis de calmer le débat à nouveau. Par la suite, le tsar aurait exprimé des regrets d'avoir proféré cette insulte et précisé que ces mots n'étaient pas destinés au pape Grégoire XIII, mais à ceux qui ne respectaient pas les commandements du Christ (S. Polčin, op. cit., p. 43).

20. D'après S. Polčin, l'invitation d'Ivan IV était hautement ambiguë. Car le premier dimanche de carême est fêté dans le monde orthodoxe comme le dimanche de l'Orthodoxie en souvenir de la victoire de la vraie foi contre les iconoclastes. À cette occasion est prononcé durant la liturgie un anathème contre tous les hérétiques, anciens et nouveaux, et on prie pour leur conversion (S. Polčin, op. cit., p. 50). 
On peut multiplier sans peine les preuves d'incompréhension réciproque. Par exemple, le jésuite italien ne manque pas d'être choqué par la toute-puissance du tsar qui combine le pouvoir temporel du monarque absolu et le pouvoir spirituel du pape, comme l'indique la tiare dont il est coiffé.

De son côté, Ivan le Terrible formule à l'adresse du légat plusieurs critiques fondées en partie sur les informations que son envoyé Ševrigin lui a fournies à son retour de Rome. Par exemple, il dénonce le refus de certains catholiques de porter la barbe, alors que Dieu a voulu que les poils poussent naturellement. En outre, dit-il, le pape se laisse vénérer comme un dieu par les fidèles, puisqu'il se fait porter sur la sedia gestatoria et se laisse baiser les pieds, ce qui est contraire à l'humilité de l'Église. Le comble de l'insolence est manifesté, selon le tsar, par le port de pantoufles ornées d'un crucifix, alors que l'Église russe interdit de porter des images sacrées au-dessous de la poitrine.

Ces incompréhensions n'empêchent toutefois pas Possevino d'être un fin observateur du monde étranger auquel il est confronté, capable de percevoir certaines habitudes et modes de pensée de ses hôtes. Ainsi, au cours de son séjour en Russie, le jésuite italien a parfaitement compris l'attachement indéfectible des Russes à leur liturgie en slavon, c'est pourquoi il préconisera par la suite l'acceptation de cette dernière par l'Église catholique dans la perspective d'un possible ralliement des Russes à l'union des Églises. De même, avant de pénétrer dans le pays du tsar, il s'est informé auprès de Tedaldi de la couleur et de la coupe des habits qu'il fallait adopter pour le costume. Ce dernier lui aurait répondu que la couleur noire ne scandaliserait personne, mais aurait insisté sur la nécessité de porter des vêtements longs à l'orientale. De même, lors de son passage en Lituanie, le jésuite italien a appris que les Russes sont extrêmement pudiques et pourraient être choqués par les représentations de la nudité dans l'art occidental, profane ou religieux. C'est pourquoi il renonce prudemment à offrir à Ivan IV une image de la Vierge à l'Enfant où certaines parties du corps apparaissent dans leur réalité la plus crue. Plus tard, lorsqu'il rentre à Rome en compagnie du diplomate Jakov Molvinianov, il prend soin, eu égard à son expérience chez Ivan IV, d'inviter le Vatican à adopter des mesures pour éviter que la pudeur des envoyés du tsar soit mise à l'épreuve : il prescrit notamment le port de vêtements longs à la manière des Russes et conseille de voiler toutes les statues nues et les tableaux du Vatican. L'expérience de Possevino et de ses compagnons de voyages est incontestablement intéressante pour l'historien des mentalités.

\section{Possevino et la Russie après la mission diplomatique}

De son séjour chez le tsar, Possevino revient convaincu que le ralliement de Moscou à l'unité religieuse sous l'égide du pape n'est pas près de se réaliser et que le Vatican s'est fait de sérieuses illusions au sujet de sa réalisation tant les préjugés anti-latins des Russes sont profondément ancrés. Pour le jésuite italien, l'union des Églises devra faire l'objet d'un long travail de sape dont l'effort principal doit être 
d'abord porté sur les populations ruthènes orthodoxes ${ }^{21}$. Possevino développe une stratégie d'apostolat missionnaire destinée à mener cette entreprise à bien dans ses écrits, en particulier son traité Moscovia dont il sera amplement question plus loin. En outre, au cours des années suivant sa mission chez Ivan IV, Possevino soutient activement le projet de conquête de la Russie élaboré par son ami le roi Étienne Bathory, projet dans lequel il voit une opportunité unique d'imposer la conversion forcée du pays au catholicisme. Il s'efforce de défendre ce projet auprès d'une Curie romaine réticente jusqu'à la mort prématurée du roi, le 12 décembre 1586, qui met fin à tout espoir de conquête militaire de la Russie 22 .

Contraint de se retirer à Padoue à partir de 1587, Possevino se lance dans divers travaux d'écriture, où il est encore question notamment de la Russie et des moyens de parvenir à l'union des Églises ${ }^{23}$. S'il n'a plus l'occasion de se rendre en Russie, il continue néanmoins de s'intéresser de près à ce pays ; c'est ainsi qu'il suivra avec attention l'épopée du premier Faux Dmitrij en 1604-1606, voyant en lui le souverain converti au catholicisme qui va rétablir l'union de l'Église russe avec Rome. En 1606, il adresse encore au pape Paul V un mémoire sur l'introduction du catholicisme en Russie. Devenu entre-temps fort âgé, Possevino se met à partir de 1607 à rédiger son autobiographie sur l'instance de Paul V et du cardinal Baronius. Il y

21. Le terme « Ruthène » employé ici désigne les Biélorusses et les Ukrainiens qui font partie, avec les Russes, de la famille des Slaves orientaux, dont les origines communes remontent à la fondation de la Russia kiévienne et à l'adoption du christianisme grec par le prince Vladimir de Kiev-Novgorod en 988. Après la destruction de la Russia kiévienne en 1237-1240 par les Mongoles, les Slaves orientaux habitant la Russia occidentale sont passés progressivement au cours du XIV ${ }^{\mathrm{e}}$ siècle sous domination lituanienne et polonaise, tandis que les Slaves orientaux habitant la Russia orientale ont subi jusqu'à la fin du Xve siècle le joug tatar-mongol avant de s'en émanciper sous l'autorité des grands-princes de Moscou. Cette longue séparation entre les Slaves orientaux et leur destin historique différent - les uns inclus dans un État de culture occidentale catholique (tempéré par l'existence d'une grande diversité ethnique et religieuse) et les autres formant un État indépendant de culture orientale et orthodoxe - contribuent à les différencier entre « Ruthènes » et « Russes ».

22. La Curie romaine est en effet réticente à ce projet, car elle préfère promouvoir son projet de ligue des princes chrétiens dirigée contre les Turcs. Possevino au contraire se montre plus intéressé par la conquête de la Russie, dont le tsar est viscéralement hostile à l'union des Églises. Pour lui, les Turcs ne constituent pas un si grand danger pour la chrétienté et font preuve d'une grande tolérance religieuse bénéfique aux catholiques séjournant dans leur empire. Au sujet du projet Bathory-Possevino et de l'attitude de Rome, voir D. Caccamo, « La diplomazia della Controriforma e la crociata: dai piani di Possevino alla "lunga guerra" di Clemente VIII », Archivio storico italiano, 128, 1970, p. 255-281; Id., « Conversione dell'Islam e conquista della Moscovia nell' attivita diplomatica e letteraria de Antonio Possevino », in Venezia e Ungheria nel Rinascimento, Atti del I Convegno di studi italo-ungheresi, Florence, 1973, p. 167-191 (Civiltà Veneziana Studi, 28).

23. Possevino est rappelé en Italie car son activité auprès d'Étienne Bathory a suscité des critiques tant du nonce pontifical en Pologne, Bolognetti, tenu à l'écart, que des Habsbourg hostiles au roi de Pologne. Au cours de sa retraite à Padoue, il rédige la Bibliotheca selecta de ratione

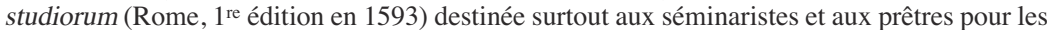
initier aux disciplines qui sont nécessaires pour leur ministère. Le sixième livre de la Bibliotheca selecta est consacré au problème de l'union des Églises. En outre, Possevino rédige 1'Apparatus sacer (Venise, $1^{\text {re }}$ édition en 1603-1606) qui est un catalogue de plus de huit mille auteurs dont il retrace la vie et les opinions. Dans cet ouvrage, Possevino consacre un paragraphe spécial aux Ruthènes. 
reparle pour la dernière fois de sa mission russe, certainement l'un des événements marquants d'une longue vie bien remplie qui s'achève en $1611^{24}$.

\section{Les premiers écrits jésuites sur la Russie}

Bien que le séjour des diplomates en Russie ait été de courte durée et étroitement circonscrit aux étapes du voyage et aux séjours chez le tsar à Starica et à Moscou, ce premier et bref contact des jésuites avec un monde différent de l'Occident est à l'origine de quatre textes d'un grand intérêt pour la connaissance de la Russie moscovite durant les dernières années du règne d'Ivan le Terrible ${ }^{25}$. Il s'agit, dans l'ordre chronologique de leur composition, des écrits suivants dont la fortune mérite d'être retracée et, sur certains points, précisée :

$1^{\circ}$ Relatio de itinere moscovitico, récit de voyage manuscrit composé par Giovanni Paolo Campana (S.J.) en septembre-octobre 1581 et adressé au général des jésuites Claudio Acquaviva $(1581-\uparrow 1615)^{26}$;

$2^{\circ}$ Litteræ Antonii Possevini, presbyteri Societatis Jesu, ad R.P. Generalem ejusdem societatis, de actis ejus missionis in Moschoviam, récit de voyage manuscrit composé par Antonio Possevino (S.J.) en avril 1582 et adressé au général des jésuites Claudio Acquaviva ${ }^{27}$;

$3^{\circ}$ Antonii Possevini ex Societate Jesu Moscovia, s. de rebus Moscoviticis et acta in conventu legatorum regis Poloniæ et Magni Ducis Moscoviæ anno 1581, traité

24. Annalium quinquaginta annorum quos sacerdos e Societate Jesu iussus est scribere iis de rebus ad quas missus est; Secunda Decas ab anno MDLXXI usque ad ann. [...] Qua decade continentur, quae mandante Gregorio XIII. Pont. Max. ad propagandam fidem atque pacificandos reges procuratura sunt in Styria, Boëmia, Polonia, Lituania, Moscovia, Germania, Italia, manuscrit conservé aux Archives romaines de la Compagnie de Jésus (OPP. NN. 336). Dans cet ouvrage, Possevino consacre encore plusieurs pages à décrire la religion des Russes (pages publiées par S. Polčin (S.J.), op. cit., p. 121-135).

25. Au sujet des écrits jésuites sur la Russie moscovite en Occident à la fin du Xvi siècle, voir S. Mund, Orbis..., op. cit., p. 52-53, 93, 95, 97, 98, 100-107, 217-220 et 417-418. Voir aussi des informations dans mon petit article publié en hommage au Professeur S. O. Śmidt: S. Mund, « Iezuitskie rasskazy o Moskovskoj Rusi konca XVI v. » (Les récits des jésuites sur la Russie moscovite à la fin du XvI siècle), in R. B. Kazakov, A. B. Bezborodov, S. M. Kaštanov, M. F. Rumjanceva, eds., Istočnikovedenie i istoriografija $v$ mire gumanitarnogo znanija : Dokl. i tez. XIV nauč. konf., Moskva, 18-19 apr. 2002 g., Moscou, 2002, p. 352355 (Rossijskij gosudarstvennyj gumanitarnyj universitet. Istoriko-arhivnyj institut. Kafedra istočnikovedenija i vspomogatel'nyh istoričeskih disciplin, Rossijskaja Akademija nauk. Arheografičeskaja komissija).

26. Manuscrit autographe conservé à Munich au Bayrisches Staatsarchiv, Jesuiten, t. 101, $\mathrm{f}^{\circ}$ 255-277. Manuscrit de la version remaniée conservé à Rome à l'Istituto Historico Germanico, Fondo Minucci, t. XXVII, 197. Récit de voyage édité par A. M. Ammann (S.J.), « Ioannis Pauli Campani S.I. Relatio de itinere moscovitico », Antemurale, 6, 1960/61, p. 1-85 [cité infra CAmpana (1960/61)]. Voir aussi traduction en allemand : A. M. Amman (S.J.), ed., « Ein russischer Reisebericht aus dem Jahre 1581 », Ostkirchliche Studien, 10, 1961, p. 156-195, 283-300.

27. Récit de voyage édité par A. I. Turgenev, Historica Russiæ Monumenta ex antiquis exterarum gentium archivis et bibliothecis deprompta, Saint-Pétersbourg, 2 vol., 1841-1848, 2, p. 388-403 [cité infra Possevino (1848)]. 
composé par Antonio Possevino (S.J.) en 1581-1582 en Russie, achevé en 15831584 en Hongrie et imprimé en 1586 à Vilna chez Johannes Velicensis ${ }^{28}$;

$4^{\circ}$ Missio Muscovitica, relation anonyme du voyage de Possevino et de Campana publiée à Rome en 1584 dans le bulletin de la Compagnie de Jésus, les Annuæ litteræ Societatis Iesu Anni M.D.LXXXII ad Patres et Fratres ejusdem Societatis ${ }^{29}$.

De tous ces textes, le traité Moscovia de Possevino est le plus connu et aussi le plus utilisé par les historiens qui s'intéressent à la politique des papes vis-à-vis de la Russie moscovite et aux descriptions de la religion orthodoxe russe par les auteurs catholiques $^{30}$. Par sa structure, cet ouvrage apparaît moins comme une étude monographique de la Russie que comme un recueil de plusieurs textes répondant à des objectifs différents, tous liés à la mission pontificale dirigée par le jésuite italien chez Ivan le Terrible et destinés à l'origine exclusivement aux agents du pouvoir politique au sein du Saint-Siège et de l'Ordre des jésuites ${ }^{31}$. Diverses circonstances ont toutefois modifié l'intention première de l'auteur de s'adresser à un public restreint et l'ont poussé au contraire à assurer une large diffusion à son ouvrage. En éditant pour la première fois la Moscovia en 1586, Possevino cherche d'une part à révéler au public l'importance du rôle joué par la Papauté dans le règlement de la guerre entre Ivan IV et Étienne Bathory bien connue en Occident grâce aux pamphlets polonais et alle-

28. Editio princeps de ce traité citée infra Possevino (1586) [Rome, Biblioteca Vaticana, Stamp. Barberini P.XI.57]. Éditions partielles par A. de Starczewski, ed., Historiae Ruthenicae scriptores exteri saeculi XVI., Berlin - Saint-Pétersbourg, 1842, t. 2. p. 273-365 ; A. I. Turgenev, ed., op. cit., 2, 1848. p. 22-41, 44-54, 57-69, 73-125. Traduction italienne : M. Olsoufieff, ed., Le lettere di Ivan il Terribile con i commentarii della Moscovia di Antonio Possevino, Florence, 1958. Traduction anglaise : H. F. Graham, ed., The Moscovia of Antonio Possevino S.J., Pittsburgh, University of Pittsburgh, 1977, p. 1-139 (UCIS Series in Russian and East European Studies, 1). Traduction russe : L. N. Godovikova, V. L. Janin, eds., A. Possevino. Istoričeskie sočinenija o Rossii XVI v. (A. Possevino. Récits historiques sur la Russie du XVI siècle), Moscou, Izdatel'stvo Moskovskogo universiteta, 1983, p. 21-188.

29. Relation de voyage publiée par P. Pierling (S.J.), ed., Antonii Possevini Missio Moscovitica ex annuis litteris Societatis Jesu excerpta, Paris, 1882, 87 p. [cité infra ANONYME (1882)]. Voir aussi la traduction en anglais par H. F. Graham, ed., «The Missio Muscovitica », Canadian American Slavic Studies /Revue canadienne-américaine d'Études slaves, 6, 1972, p. 437-477 et la traduction en russe par L. N. Godovikova, ed., " "Moskovskoe posol'stvo" Antonio Possevino » (La Missio Muscovitica d'Antonio Possevino), Vestnik Moskovskogo Universiteta. Serija 9. Istorija, 5, 1970, p. 87-100 et L. N. Godovikova, V. L. Janin, eds., op. cit., p. 189-212.

30. Analyse de ce traité par S. Polčin (S.J.), op. cit., p. 22-120 ; A. Kadič, op. cit., p. 75-80 ; H. F. Graham, ed., The Moscovia..., op. cit., p. XIII-XXXII et 140-180 ; L. N. Godovikova, V. L. Janin, eds., op. cit., p. 5-20 et 232-258.

31. Cf. e.a. A. Kappeler, Ivan Groznyj im Spiegel der ausländischen Druckschriften seiner Zeit ; ein Beitrag zur Geschichte des westlichen Russlandbildes, Berne - Francfort, Herbert et Peter Lang, 1972, p. 84-85 (Geist und Werk des Zeiten, 33) ; A. Kadič, op. cit., p. 75-76 et W. Leitsch, Berichte über den Moskauer Staat in italienischer Sprache aus dem 16. Jahrhundert. Eine quellenkritische Studie mit besonderer Berücksichtigung der italienischen Übersetzung der Moscovia Herbersteins, Vienne - Cologne - Weimar, Böhlau Verlag, 1993, p. 54-55 et n. 77 (Wiener Archiv für Geschichte des Slawentums und Osteuropas, 15). Selon W. Leitsch, il semble que Possevino n'a pas voulu écrire de description chorographique de la Russie parce que cela avait déjà été fait avant lui par des auteurs comme Giovio et Herberstein, auxquels il renvoie volontiers dans son livre. 
mands ${ }^{32}$. D'autre part, il est soucieux de mettre en valeur sa contribution personnelle comme médiateur dans les délicates négociations entre les Polonais-Lituaniens et les Russes. C'est dans cette perspective qu'il a inséré à la fin de son traité un ensemble important d'actes et de correspondance diplomatiques de cette époque cruciale. À ces deux objectifs, s'en ajoute un troisième, apparu en cours de rédaction. En effet, Possevino a déjà commencé la préparation de son traité (c.1582/1583) lorsque paraît en 1584 à Cracovie une chronique des campagnes militaires d'Étienne Bathory contre les Russes, écrite par le secrétaire du roi, Reinhold Heidenstein et intitulée De Bello Moscovitico quod Stephanus rex Poloniæ gessit Commentariorum libri VI ${ }^{33}$. La publication de cet ouvrage aurait, semble-t-il, incité le jésuite italien à achever son traité le plus rapidement possible, car il reprochait à Heidenstein de ne pas avoir suffisamment mis en valeur le succès polonais obtenu grâce à l'arbitrage pontifical dans le règlement du conflit, et entendait remédier à cette lacune ${ }^{34}$.

Les textes regroupés dans la Moscovia ont été, en dehors de la correspondance diplomatique, composés par Possevino pendant et après sa mission en Russie. Dans l'editio princeps de 1586, ils apparaissent selon l'ordre suivant :

$1^{\circ}$ De Rebus Moscoviticis commentarius ad Gregorium XIII. Pont. Max.

Adressé à Grégoire XIII, ce texte a été écrit par Possevino vers 1583, c'est-àdire après la fin de sa mission en Russie ${ }^{35}$. Dans une première partie, 1'auteur dresse

32. Au sujet des pamphlets occidentaux consacrés à la Russie d'Ivan le Terrible, voir les travaux fondamentaux de A. Kappeler: «Die letzten Opričninajahre (1569-1571) im Lichte dreier zeitgenössischer deutscher Broschüren », Jahrbücher für Geschichte Osteuropas, 19, 1971, p. 1-30 ; Ivan Groznyj..., op. cit., passim ; « Die deutschen Russlandschriften der Zeit Ivans des Schrecklichen », in F. Kaiser, B. Stasiewski, eds., Reiseberichte von Deutschen über Russland und von Russen über Deutschland, Cologne - Vienne, 1980, p. 1-23 (Studien zum Deutschtum im Osten, 15) ; « Die deutschen Flugschriften über die Moskowiter und Iwan den Schrecklichen im Rahmen der Russlandliteratur des 16. Jahrhunderts », in M. Keller, ed., Russen und Russland aus deutscher Sicht 9-17. Jahrhundert, Munich, 1985, p. 150-182 (Westöstliche Spiegelungen, Reihe A, 1).

33. Ayant reçu une excellente formation à l'université de Wittenberg, en Italie et en France, Reinhold Heidenstein $(* 1553 ?-\dagger 1620)$ commence sa carrière comme secrétaire du duc de Prusse avant de passer au service du roi de Pologne. Il a assisté directement, en tant que secrétaire royal, aux campagnes militaires d'Étienne Bathory contre Ivan le Terrible, ce qui l'a amené à composer sa chronique De Bello Moscovitico. Au sujet de Heidenstein et de sa chronique, voir J. A. Limonov, Kul'turnye svjazi Rossii s evropejskimi stranami $v$ XV-XVII VV. (Les relations culturelles de la Russie avec les pays européens, $X V^{e}-X V I I^{e}$ s.), Leningrad, Nauka, 1978, p. 168-199 et H. F. Graham, « Heidenstein, Reinhold (1556-1620) », in J. L. Wieczynski, Modern encyclopaedia of Russian and Soviet history, Gulf Breeze (Floride), 13, 1979, p. 241-242. Selon le père Pierling, Heidenstein aurait personnellement offert en janvier 1586 un exemplaire de sa chronique à Possevino qui avait auparavant essayé en vain d'obtenir de Bathory le droit d'exercer une censure sur cette œuvre avant sa publication. (P. Pierling (S.J.), La Russie..., op. cit., 2, p. 232).

34. Sur les motifs qui ont incité Possevino à écrire la Moscovia, cf. P. Pierling (S.J.), La Russie..., op. cit., 2, p. 233 ; H. F. Graham, ed., The Moscovia..., op. cit., p. XIII et L. N. Godovikova, V. L. Janin, eds., op. cit., p. 232. Le père Pierling voit dans la chronique de Heidenstein le motif qui a poussé Possevino à publier sa Moscovia. Cette affirmation est réfutée par L. N. Godovikova qui montre clairement que la préparation de la Moscovia est antérieure à la parution de la chronique de Heidenstein. Cette dernière a servi, selon l'historienne soviétique, tout au plus d' « accélérateur » dans la réalisation du traité.

35. Possevino (1586), $\mathrm{f}^{\circ} 1-46 \mathrm{v}^{\circ}$. Cité sous le nom «Commentaire I » en fonction de l'ordre de publication dans la Moscovia même si sa rédaction est plus tardive que celle du « Commentaire II ». 
pour le pape un état du système politique russe : il met notamment en évidence les pouvoirs considérables d'Ivan le Terrible, sa personnalité, sa disposition d'esprit à l'égard du schisme orthodoxe et de l'union des Églises, évoque les membres influents de son entourage et décrit le cérémonial de réception des diplomates étrangers à la Cour moscovite. Possevino présente ici des informations tirées de ses observations personnelles et de ses lectures ainsi que des témoignages de ses compagnons, le père Drenocky et le frère Morieno, restés auprès du tsar pendant qu'il s'occupait de la médiation entre les diplomates polonais-lituaniens et russes. Dans la seconde partie, il évalue les chances et les perspectives d'une diffusion du catholicisme en Russie et présente, en raison de son expérience du terrain, un projet d'ambassade pontificale avec toutes les consignes nécessaires pour assurer le succès d'une entreprise aussi difficile.

$2^{\circ}$ Alter commentarius de Rebus Moscoviticis, ad religionem præsertim spectantibus in Moscovia, mandato eiusdem Gregorii XIII. Pont. Max. in prima eius ad Moscum Legatione conscriptus

Ce texte également adressé à Grégoire XIII a été composé par Possevino après son départ de Starica en septembre 1581 au moment où son compagnon Campana écrivait son rapport au général des jésuites Acquaviva ${ }^{36}$. Possevino commence par se livrer à une description générale de l'Église russe conformément aux instructions reçues à Rome. Ensuite il évoque longuement les obstacles qui s'opposent à l'introduction du catholicisme en Russie. Il convient de noter qu'à cette époque Possevino n'a pas encore participé aux colloques religieux avec Ivan IV, mais qu'il est déjà conscient des difficultés qu'il rencontrera pour faire accepter l'union des Églises. Enfin, comme dans le commentaire précédent, Possevino développe la stratégie que devra déployer le Saint-Siège afin de promouvoir le catholicisme en Russie.

$3^{\circ}$ Colloquia de religione catholica publice ab auctore habita cum Magno Moscoviæ Duce

Ce texte est le procès-verbal des trois colloques tenus en public par Possevino et Ivan IV au Kremlin à Moscou les 21 et 23 février et le 4 mars $1582^{37}$. Il montre que le jésuite italien a essayé en vain d'obtenir le ralliement du tsar à l'union des Églises mais a mené brillamment la joute oratoire contre le tsar au point de susciter l'ire du souverain.

$4^{\circ}$ Capita quibus Græci et Rutheni à Latinis in rebus Fidei dissenserunt, postquam ab Ecclesia Catholica Græci descivere

Ce texte a été composé pour le tsar après le deuxième colloque public ${ }^{38}$. Ivan IV lui demandait de présenter les différentes divergences dogmatiques entre l'Église catholique et l'Église russe. Si Possevino y manifeste une certaine souplesse en

36. Possevino (1586), $\mathrm{f}^{\circ} 1-25$. Cité sous le nom « Commentaire II » en fonction de l'ordre de publication dans la Moscovia même s'il a été composé avant le "Commentaire I ».

37. Possevino (1586), fo 1-15. Texte analysé par S. Polčin, op. cit., p. 36-59.

38. Possevino (1586), $\mathrm{f}^{\circ} 1-10 \mathrm{v}^{\circ}$ et $101-112 \mathrm{v}^{\circ}$. Il faut noter ici une erreur dans la numérotation des folios qui passent de $10 \mathrm{v}^{\circ}$ à 101 dans le livre. 
matière de pratique liturgique, il apparaît en revanche rigide dans les affaires de dogme, dressant un catalogue de toutes les erreurs dont les Grecs et les Russes se sont rendus coupables ${ }^{39}$.

À ces quatre textes, s'ajoute un traité que Possevino a composé à son arrivée à Moscou en janvier 1582 pour réfuter devant Ivan IV les calomnies répandues à propos du pape au Kremlin par les marchands anglais « hérétiques » ${ }^{40}$.

La Moscovia de Possevino est le premier grand traité original sur la Russie moscovite publié en Occident depuis les Rerum Moscoviticarum Commentarii de Herberstein, dont la parution en 1549 avait en son temps marqué une étape considérable dans l'évolution des connaissances occidentales à propos du pays des tsars ${ }^{41}$. Si la description de la Russie dans la Moscovia est moins volumineuse que dans celle des Rerum Moscoviticarum Commentarii, le jésuite italien porte, à l'instar du diplomate impérial, un intérêt particulier au système politique en Russie et à la religion pratiquée par ses habitants ${ }^{42}$. Comme Herberstein avant lui, Possevino souligne abondamment le pouvoir illimité du tsar, qui exerce un contrôle strict sur ses sujets et est toujours prêt à écraser sans merci le moindre acte de désobéissance et la moindre manifestation d'une indépendance d'esprit ${ }^{43}$. Le tsar est présenté comme l'arbitre suprême qui dispose totalement des biens et de la vie de ses sujets. La Russie lui appartient en propre selon les termes du jésuite italien : «Le prince seul contrôle tout. Les villes, les forteresses, les villages, les maisons, les champs, les domaines, les forêts, les lacs, les rivières, les titres et les offices témoignent tous dans cet immense pays du pouvoir énorme et des ressources qu'il possède $»^{44}$.

39. Texte analysé par S. Polčin, op. cit., p. 67-76.

40. Scriptum Magno Moscoviæ Duci traditum, cum Angli mercatores eidem obtulissent librum, quo hæreticus quidam ostendere conabatur Pontificem Maximum esse Antichristum.

41. Au sujet de l'impact du traité de Herberstein sur la connaissance du monde russe en Occident, voir S. Mund, Orbis..., op. cit., p. 393-457. Entre les traités de Herberstein et de Possevino, est parue à Cracovie en 1578 une description de la Russie présentée dans le cadre d'une description générale de l’Europe Orientale. Son auteur, Alessandro Guagnini (*c.1538-†1614), était un mercenaire italien au service du roi de Pologne, commandant de la place forte de Vitebsk non loin de la frontière russe. Mais contrairement au traité de Possevino qui est une œuvre originale, la description de la Russie chez Guagnini est un plagiat du traité de Herberstein. Au sujet de la description de Guagnini, voir e.a. C. Cipolla, « Un Italiano nella Polonia e nella Svezia tra il XVI e XVII secolo », Miscellanea di Storia italiana, Turin, 26, 1887, p. 547657 ; H.F. Graham, «Guagnini, Alessandro (1538?-1614) », in J. L. Wieczynski, Modern encyclopaedia of Russian and Soviet history, Gulf Breeze (Floride), 13, 1979, p. 173-176.

42. À titre d'exemple, la géographie de la Russie fait l'objet de quelques lignes seulement chez Possevino, alors que Herberstein lui consacre plusieurs pages de son traité. De même, Herberstein fait une description systématique des sacrements de l'Église orthodoxe russe, alors que Possevino en évoque uniquement deux. Enfin, Herberstein insère dans son traité des textes religieux et géographiques russes auxquels il a eu accès durant son séjour à Moscou, ce qui n'est pas le cas de Possevino.

43. Le pouvoir du tsar est étudié dans Possevino (1586), Commentaire I, $\mathrm{f}^{\circ} 8 \mathrm{v}^{\circ}-13$, et $28 \mathrm{v}^{\circ}-31$ et Commentaire II, $\mathrm{f}^{\circ} 3 \mathrm{v}^{\circ}-7$. Pour une analyse de la représentation du tsar chez Herberstein, voir S. Mund, Orbis..., op. cit., p. 271-275.

44. Possevino (1586), Commentaire I, $\mathrm{f}^{\circ} 9$ : « Cum in unum ipsum Principem omnia congerantur, civitates, oppida, pagi, domus, agri, praedia, sylvae, lacus, flumina, honor ac dignitas, nihil in tam vasto terrarum tractu non maximum videri potest earum virium, et opum quibus polleat. » 
La servilité des Russes est telle que même les boyards et les nobles reconnaissent que tout, y compris leur santé, dépend du tsar. Pour preuve de ce comportement servile, Possevino répète le dicton russe, déjà cité par Herberstein, selon lequel seul Dieu et le tsar savent tout ${ }^{45}$. Plus encore que le diplomate impérial, il souligne combien le pouvoir absolu du tsar repose sur la peur qu'il inspire à ses sujets qui le craignent plus qu'ils ne le vénèrent ${ }^{46}$. Cette peur s'observe, d'après le jésuite italien, dans les rapports des Russes à l'égard des étrangers, avec lesquels ils n'osent pas parler de peur d'être l'objet de soupçons. Cette atmosphère de crainte, Possevino affirme l'avoir ressentie chez les Russes à maintes reprises lors de son séjour. Il est vrai qu'il a séjourné dans un pays qui a connu quelques années auparavant la terrible période de l'Opričnina au cours de laquelle Ivan le Terrible et ses sbires ont assassiné en toute impunité de nombreuses personnes et dévasté des villes entières. Bien qu'il ne cite jamais le terme Opričnina, comme le fera plus tard le diplomate anglais Giles Fletcher, Possevino a bien remarqué les effets du pouvoir «tyrannique » d'Ivan le Terrible sur son pays, dont il évoque notamment la dépopulation et la grande misère ${ }^{47}$.

Un autre signe de la puissance du tsar qui retient l'attention de Possevino dans la Moscovia est le faste de sa cour, en particulier lors de la cérémonie de réception d'un ambassadeur étranger. Possevino en évoque les aspects principaux - la procession vers le palais, la cérémonie de l'audience officielle chez le tsar, paré de ses plus beaux vêtements d'apparat et entouré de ses courtisans richement vêtus, le banquet, etc. - sur base de son expérience personnelle ${ }^{48}$. Là encore son témoignage est proche de celui de Herberstein dont il confirme la qualité des informations à ce sujet. Comme le diplomate impérial, mais sur un ton plus agressif, le jésuite italien évoque notamment la coutume du tsar, qu'il juge infamante, de se laver les mains dans une bassine d'argent située à côté de son trône, immédiatement après avoir salué un chrétien latin ${ }^{49}$.

La religion orthodoxe est le second aspect du monde russe qui retient le plus l'attention de Possevino, tout comme celle de Herberstein avant lui ${ }^{50}$. Ici encore la description fournie par le jésuite italien ne diffère guère de celle du diplomate impérial $^{51}$. Possevino note que la Russie compte un métropolite, deux archevêques et

45. Possevino (1586), Commentaire II, $\mathrm{f}^{\circ} 3 \mathrm{v}^{\circ}: \ll[\ldots]$ ut interrogati saepius respondeant: Solus Deus, \& magnus Dominus, (hoc est, Princeps) hoc scit : ipse noster magnus Dominus novit omnia.» Ce dicton est cité par HerbersteIn (1556), p. 15 [édition utilisée : Londres, British Library, $\left.{ }^{\circ} \mathrm{G} .7213\right]$ : « [...] si quispiam de re aliqua incerta \& dubia quaerit, respondere communiter solent : Deus scit, \& magnus princeps. »

46. Possevino (1586), Commentaire I, $\mathrm{f}^{\circ} 11 \mathrm{v}^{\circ}-12$.

47. Giles Fletcher, Of the Russe Common Wealth or manner of governement by the Russe Emperour, (commonly called the Emperour of Moscovia) with the manners, and fashions of the people of that country, Londres, Thomas Charde, 1591 (rééd. en 1966), $\mathrm{f}^{\circ} 25 \mathrm{v}^{\circ}$.

48. Possevino (1586), Commentaire $\mathrm{I}, \mathrm{f}^{\circ} 15 \mathrm{v}^{\circ}-21$.

49. Possevino (1586), Commentaire I, $\mathrm{f}^{\circ} 30 \mathrm{v}^{\circ}-31$ et Commentaire II, $\mathrm{f}^{\circ} 3$.

50. La religion des Russes est étudiée dans Possevino (1586), Commentaire II, $\mathrm{f}^{\circ}$ 1-13.

51. HERBERSTEIN (1556), p. 27-47. 
huit évêques, ce qui est, selon lui, peu pour un pays aussi vaste. À l'instar de Herberstein, il s'intéresse au statut du métropolite, des évêques et des prêtres et aux fonctions qu'ils exercent. Le métropolite est décrit comme le chef de l'Église russe, choisi par le tsar, consacré ensuite par deux ou trois évêques. Le lien ancien entre l'Église russe et le patriarche de Constantinople, explique Possevino, est symbolisé par le fait que le tsar donne encore chaque année à ce dernier une somme de cinq cents pièces d'or. Les évêques, toujours choisis parmi les moines, sont célibataires, ne mangent jamais de viande et font l'objet d'un grand respect. Contrairement à leurs collègues catholiques, ils ne visitent pas leur diocèse mais administrent celuici à travers leurs représentants. Les prêtres ou popes retiennent l'attention de Possevino surtout par leur statut matrimonial. Tout comme le diplomate impérial avant lui, le jésuite italien note qu'ils peuvent se marier une seule fois avant de devenir prêtres. Lorsque l'épouse du prêtre meurt, ce dernier, pour continuer à officier, doit devenir moine. Si au contraire il décide de se remarier, il renonce automatiquement à la prêtrise. Au sujet des moines, Possevino affirme qu'ils appartiennent au même Ordre fondé par saint Basile et sont en général très ignorants ${ }^{52}$.

Possevino s'intéresse également à certains sacrements pratiqués par l'Église orthodoxe, à savoir le baptême par immersion et l'extrême-onction, au culte particulier voué par les Russes à saint Nicolas et aux différentes périodes de jeûne. Par ailleurs, il note, tout comme Herberstein avant lui, que les Russes ordinaires ne cessent jamais de travailler y compris durant les jours de fête, tels que Noël et Pâques, contrairement aux nobles. Toujours selon le jésuite italien, le commun peuple se contente de se signer plusieurs fois devant les icônes qu'il vénère avec une grande dévotion. Les femmes et les filles de la noblesse se rendent rarement à l'église, excepté le jour de Pâques pour y recevoir l'Eucharistie. Durant la messe, il n'y a pas de prêche :

Les fidèles écoutent simplement pendant que les popes lisent les Vies des saints, ou de personnes qu'ils vénèrent comme saints, et des passages de certaines homélies, en particulier celles de saint Jean Chrysostome, comme je l'ai déjà évoqué plus haut. Les fidèles restent debout pour prier, inclinant parfois leur front jusqu'au sol, ce qui est aussi leur coutume à certaines occasions lorsqu'ils saluent des membres de la noblesse ou demandent l'aumône ${ }^{53}$.

Bien que Possevino présente la religion des Russes à partir de sa propre expérience et de celle de ses compagnons, il lui arrive d'emprunter parfois directement des informations au traité de Herberstein. C'est notamment le cas lorsqu'il évoque le séjour du moine Maxime le Grec du Mont Athos venu à Moscou à la demande de Vasilij III pour

52. Saint Basile de Césarée $(* 329-\uparrow 379)$ est en effet, avec saint Pacôme $(* 287-\uparrow 347)$ en Égypte, un des organisateurs du monachisme cénobitique oriental.

53. Possevino (1586), Commentaire II, $\mathrm{f}^{\circ} 11-11 \mathrm{v}^{\circ}$ : «Concionatores non habent ; sed tantum, quas diximus, vitas Sanctorum, vel eorum, quos pro sanctis venerantur, atque homeliae partem [ $\left.\mathrm{f}^{\circ} 11\right]$ ut dixi, (ex D. praesertim Chrysostomo) à Poppis suis audiunt. Orantes stant, interdumque fronte percutiunt terram : quod illis quoque in salutandis primariis viris aliquando, \& in eleemosyna petenda solemne est. » 
corriger les erreurs contenues dans les livres sacrés russes ${ }^{54}$. Si Possevino s'appuie à plusieurs reprises sur le traité de Herberstein, il lui arrive aussi d'employer celui de Giovio, mentionné plus haut, lequel avait consacré plusieurs paragraphes de sa description de la Russie au début du XVI ${ }^{e}$ siècle à la religion orthodoxe russe ${ }^{55}$. C'est ainsi qu'il lui emprunte l'information selon laquelle les Russes ont reçu la foi chrétienne des Grecs il y a cinq cents ans. Possevino cite notamment l'historien italien pour dire qu'il n'a pas pu vérifier son affirmation selon laquelle les écrits des quatre Docteurs de l'Église latine et d'autres Pères de l'Église sont connus des Russes ${ }^{56}$.

Qu'il s'agisse de la représentation de la religion orthodoxe russe ou de la description du pouvoir tyrannique du tsar, la Moscovia de Possevino ne se distingue guère des Rerum Moscoviticarum Commentarii de Herberstein. Cette similitude s'explique probablement par le fait que le traité de Herberstein a dû être la principale source d'information de Possevino sur la Russie avant son départ pour ce pays et a forgé d'une certaine manière sa perception initiale du pays, laquelle s'est par la suite enrichie de l'expérience du voyage. Sans citer nommément Herberstein, Possevino reconnaît dans la préface du Commentaire I qu'il a choisi comme méthode de comparer son expérience personnelle en Russie avec ce qu'il a lu et entendu auparavant à propos de ce pays :

[...] il me fut facile de comparer ce que j'avais noté à partir de différents ouvrages et ce que j'avais entendu à propos du Moscovite [Ivan IV] de la bouche de divers diplomates, d'abord en Suède, puis en Pologne, ainsi que des souverains mêmes de ces royaumes ${ }^{57}$.

C'est pourquoi sans fondamentalement changer la représentation de la religion orthodoxe russe et de la tyrannie du tsar contenue dans les Rerum Moscoviticarum Commentarii, avec laquelle il est d'accord, le jésuite italien complète le diplomate impérial en apportant des précisions supplémentaires sur certains points particuliers qui enrichissent la connaissance occidentale de ces deux aspects fondamentaux de la Russie moscovite. À titre d'exemple, là où Herberstein évoquait l'intervention du tsar dans les affaires religieuses, Possevino affirme pour sa part que le tsar se prétend à la fois empereur et pontife suprême et adopte à cet effet les attributs symboliques

54. Possevino (1586), Commentaire II, $\mathrm{f}^{\circ} 1$ et Herberstein (1556), p. 42-43. Maxime Trivolis, surnommé Maxime le Grec $(* c .1470-\uparrow 1556)$, est connu comme humaniste formé en Italie et traducteur d'écrits religieux. En 1517, il se rend à Moscou dans le cadre d'une ambassade du patriarche de Constantinople. Il y reste et travaille sur les traductions de textes canoniques à la demande de Vasilij III. Mais bientôt mêlé à la controverse religieuse sur le bien-fondé des richesses de l'Église, il est condamné en 1525 pour hérésie et exilé loin de Moscou. Voir à ce sujet J. V. Haney, From Italy to Muscovy, the life and works of Maxim the Greek, Munich, W. Fink, 1973 (Humanistische Bibliothek, Reihe 1 : Abhandlungen, 19).

55. Giovio (1525), $\mathrm{f}^{\circ} \mathrm{D} 1 \mathrm{v}^{\circ}-\mathrm{D} 3 \mathrm{v}^{\circ}$ [editio princeps utilisée : Cambridge, University Library, $\left.\mathrm{n}^{\circ} \mathrm{N}^{*} .4 .354\right]$.

56. Possevino (1586), Commentaire II, $\mathrm{f}^{\circ} 2 \mathrm{v}^{\circ}$ et $8 \mathrm{v}^{\circ}$.

57. Possevino (1586), Commentaire $I, f^{\circ} 1 v^{\circ}: \ll[\ldots]$ facilius mihi fuit, ea, quae ex historiis adnotaveram, et quae ab variis Legatis, et in Suecia primum, deinde in Polonia, ab ipsismet eorum Regnorum Regibus non semel de Mosco audiveram, cum re praesenti conferre. » 
de ce dernier, à savoir les vêtements et la tiare ${ }^{58}$. De même, il ajoute comme autre signe du despotisme du tsar le fait que celui-ci interdit à ses sujets d'être plus instruits et plus cultivés que lui-même de peur qu'ils n'échappent à son contrôle ${ }^{59}$. Un dernier exemple concerne la description de la cérémonie des funérailles, inexistante chez Herberstein, à laquelle Possevino consacre quelques lignes :

Lorsque le défunt est porté à son ultime demeure, les popes et les laïcs le suivent en tenant de petites chandelles dans leurs mains sans porter de croix devant eux. Une sainte icône est attachée sur la poitrine du défunt, qui est recouvert d'un linceul, excepté à la tête. Ils chantent seulement ce Trisagion : « Saint, Saint, Saint, Dieu puissant et immortel ». Quand le corps du défunt est arrivé au lieu de son repos éternel, ils disent « Ô Seigneur, souviens-toi de l'âme de cette personne », prononcent d'autres mots semblables provenant des liturgies grecques ou de saint Denis l'Aréopagite, et baisent le corps du défunt. Si le défunt était noble, le métropolite et un évêque résidant dans la ville accompagnent la procession funéraire jusqu'au lieu du repos ${ }^{60}$.

Parfois aussi le jésuite italien corrige la vision du diplomate impérial. À titre d'exemple, si les deux auteurs sont d'accord pour dire que les Russes ont reçu la foi des Grecs, Herberstein affirme qu'ils ont préservé celle-ci intacte depuis les origines. Possevino, au contraire, prétend qu'à son époque ils diffèrent des Grecs en de nombreux aspects ${ }^{61}$.

Alors que Herberstein et Possevino étudient les mêmes aspects du monde russe et en fournissent une image à peu près similaire dans leurs traités, leur intérêt est toutefois motivé par des objectifs très différents. En publiant les Rerum Moscoviticarum Commentarii, Herberstein voulait en partie dénoncer la vision idéaliste de la Russie présentée par le théologien allemand Johann Fabri dans un traité intitulé Moscovitarum iuxta mare glaciale Religio ${ }^{62}$. Ce dernier y faisait entre autres l'éloge

58. Possevino (1586), Commentaire I, $\mathrm{f}^{\circ} 3 \mathrm{v}^{\circ}-4$ et Herberstein (1556), p. 27 et 28.

59. Possevino (1586), Commentaire I, fo 29.

60. Possevino (1586), Commentaire II, $\mathrm{f}^{\circ} 11-11 v^{\circ}$ : « Cum funus effertur, id Poppi, Laicique, candelis quibusdam parvulis ardentibus, quas gerunt in manibus, prosequuntur, nulla praelata cruce : imagine tantum pia de mortui pectori haerente, qui sic linteamine totus obvoluitur, sola ut facies cerni possit. Nihil vero aliud concinunt, praeter illud trisagion, Sancte DEUS, Sancte fortis, Sancte \& immortalis. Cum autem cadaver mandant sepulturae, Recordare, inquiunt, Domine animae huius: ac quaedam in eum sensum, ex Graecorum Liturgiis, aut ex D. Dionysio Areopagita, verba proferunt. Mortuum osculantur : si quis nobilior moritur, hunc Metropolita, quique alius adest in civitate Episcopus, comitantur, quousque in sepulturam illatum sit cadaver. »

61. Herberstein, 1556, p. 27 : «Russia coepit, et in hunc usque diem in fide Christi ritu Graeco perseverat » et Possevino (1586), Commentaire I, $\mathrm{f}^{\circ} 15 \mathrm{v}^{\circ}$ : « fidei Graecae noticiam Ruteni hauserint, licet in multis iam different. »

62. Évêque de Vienne depuis 1530 et confesseur de l'archiduc Ferdinand de Habsbourg, frère de l'empereur Charles Quint, Johann Fabri $(* 1478-\uparrow 1541)$ est surtout connu pour ses polémiques contre la Réforme de Luther en Allemagne. Il a écrit son traité sur la religion des Russes, à la suite d'un entretien avec des diplomates russes envoyés par Vasilij III auprès de Charles Quint en automne 1525, dans le but de trouver de nouveaux arguments théologiques contre ses adversaires luthériens. Ce traité, dont le titre complet est Ad Serenissimum Principem Ferdinandum Archiducem Austrix, Moscovitarum iuxta mare glaciale Religio, a D. Ioanne Fabri ædita, paraît pour la première fois à Bâle en 1526. 
de l'autorité du souverain russe préservant son pays des désordres que connaissait à l'époque l'Empire germanique aux prises avec la Réforme luthérienne. Herberstein cherchait au contraire à souligner par de multiples exemples le despotisme et le régime arbitraire imposés par Vasilij III à l'ensemble de ses sujets, noblesse et clergé compris ${ }^{63}$. L'intérêt de Herberstein pour la religion des Russes s'expliquait encore par la volonté de contredire Fabri qui s'efforçait, dans sa polémique antiluthérienne, de démontrer la grande similarité entre l'Église catholique romaine et l'Église orthodoxe russe, voyant en cette dernière une alliée naturelle de la première contre l'hérésie de la Réforme. Le diplomate impérial au contraire soulignait, sources écrites russes à l'appui, la profonde inimitié des Russes orthodoxes à l'égard de la chrétienté latine ${ }^{64}$.

L'intérêt de Possevino pour le régime politique de la Russie et pour son Église orthodoxe s'inscrivent dans des objectifs différents de ceux du diplomate impérial, objectifs moins intellectuels et plus pratiques. Comme il l'explique dans la préface du Commentaire I, Possevino s'intéresse au pouvoir et à la personnalité d'Ivan IV car il cherche à évaluer la possibilité pour le Saint-Siège de développer des relations amicales avec le tsar qui seraient bénéfiques pour la chrétienté romaine :

Avec l'aide de Dieu, j'ai l'intention dans ce Commentaire d'exposer l'état présent des choses en Russie. Je parlerai de ce que l'on peut attendre d'Ivan Vasil'evič, l'actuel prince, et des opportunités éventuelles pour le Saint-Siège d'établir des relations amicales avec lui afin d'aboutir à l'introduction d'une

63. Outre la volonté de réfuter les arguments de Fabri, Herberstein voulait faire prévaloir son expérience de témoin oculaire de la Russie contrairement à ses prédécesseurs Giovio et Fabri qui décrivaient la Russie sans l'avoir visitée personnellement. Pour une étude du lien entre les traités de Fabri et de Herberstein, voir e.a. F. Kämpfer, « Siegmund von Herbersteins "Rerum Moscoviticarum Commentarii”" als religionsgeschichtliche Quelle», in G. Pferschy, ed., Siegmund von Herberstein, kaiserlicher Gesandter und Begründer der Russlandkunde und die europäische Diplomatie, Graz, Akademische Druck- und Verlagsanstalt, 1989, p. 147-163 (Veröffentlichungen der Steiermärkischen Landesarchivs, 17); rééd. in F. Kämpfer, ed., Das Russlandbuch Sigismunds von Herberstein «Rerum Moscoviticarum Commentarii » 1549-1999 Beiträge zu Ehren der internationalen Tagung im Oktober 1999 an den Universität Münster, Hambourg, Ingrid Kämpfer Verlag, 1999, p. 37-62 ; F. Kämpfer, « Herbersteins nicht eingestandene Abhängigkeit von Johann Fabri aus Leutkirch », Jahrbücher für Geschichte Osteuropas, 44, 1996, p. 1-25 ; rééd. in F. Kämpfer, ed., op. cit., p. 64-107 ; O. F. Kudrjavcev, « Das ambivalente Bild Russlands. Sigismund von Herberstein und seine Vorgänger », in F. Kämpfer, R. Frötschner, eds., op. cit., p. 101-114.

64. Pour montrer l'hostilité des Russes à l'égard de la Papauté et des catholiques en général, Herberstein insère dans son traité trois textes théologiques « russes » de la fin du XIe siècle, qui parlent d'eux-mêmes selon lui. Le premier est une épître du métropolite de Russia Jean II Prodrome (1080-†1089) adressée à l'antipape Clément III (1080-1089-†1100), dans laquelle il expose toutes les déviances reprochées par l'Église orientale aux catholiques. Le deuxième, intitulé Pravila cerkovnaja ot svjatyh knig v kratce Jakovu černoriz'cju (Réponses canoniques tirées des Saintes Écritures résumées pour le moine Jakov) et composé par ce même métropolite, traite des rites et de la discipline liturgique requis par l'Église orientale ; parmi les thèmes abordés figure notamment la restriction des contacts avec les catholiques. Quant au troisième, il s'agit d'un autre traité liturgique important de l'Église russe, écrit dans la première moitié du XII siècle, à savoir les Voprosy Kirika, Savvy i Il'i s otvetami Nifonta, episkopa Novgorodskogo (Les questions de Kirik, Savva et Il'ja avec les réponses de Nifont, évêque de Novgorod). Dans ce dernier texte, il est beaucoup question des positions de l'Église orientale face aux « hérétiques latins ». Textes publiés dans HerbersteIN (1556), p. 30-37. 
forme de culte plus pure dans ce vaste pays du nord-est ou d'inciter les princes chrétiens à conclure une alliance avec lui. Il faut désirer par-dessus tout qu'une forme plus sincère de christianisme soit établie dans ce royaume ${ }^{65}$.

L'intérêt de Possevino pour l'Église orthodoxe russe s'inscrit également dans la perspective d'un combat et de la promotion du catholicisme en Russie. À la fin de ses deux Commentaires, Possevino développe longuement pour le pape une stratégie de conquête de l'orthodoxie russe ${ }^{66}$. Partant du constat que l'union des Églises n'est pas prête de se faire avec Moscou en raison de l'hostilité viscérale du tsar à cette idée et de l'absence totale de liberté d'action dans son pays due au régime despotique en place, Possevino envisage la conversion de la Russie seulement dans le long terme. Celle-ci ne doit être aucunement abandonnée, pense-t-il, car il s'agit non seulement du salut des habitants de ce pays immense mais aussi de la possibilité entrevue par lui de promouvoir l'évangélisation de toute l'Asie. Pour reprendre ses propres mots :

[...] il faut absolument tenir pour certain que l'ouverture de la route de l'Asie pour la propagation de la foi du Christ est beaucoup moins coûteuse et moins dangereuse à travers la Russie qu'à travers toutes les autres régions du monde ${ }^{67}$.

En bon jésuite, Possevino reconnaît l'importance primordiale de l'éducation pour assurer le succès de la mission en Russie ${ }^{68}$. En effet, de son séjour au pays du tsar, il est revenu convaincu de l'ignorance généralisée des Russes qui sont pour cette raison pleins de préjugés profondément enracinés à l'égard du catholicisme et ne se rendent absolument pas compte du fait qu'ils pratiquent une religion « schismatique ». Pour remédier à cette ignorance, le jésuite italien envisage la nécessité de former des Russes dans des séminaires et des collèges spécialement fondés pour eux à Rome et en Bohême. Il se rend néanmoins compte que cet objectif est difficile à atteindre car les Russes sont rarement autorisés par le tsar à sortir de leur pays. C'est pourquoi il préconise aussi de porter un effort éducatif particulier à l'égard des Ruthènes qui habitent les territoires biélorusse et ukrainien sous suzeraineté polonaise-lituanienne et dont les liens linguistiques, culturels,

65. Possevino (1586), Commentaire I, $\mathrm{f}^{\circ} 1$ : «Quinam rerum status in Moscovia, quidque de ipso Ioanne Basilii Moscorum Principe, qui nunc rerum potitur, sperandum sit, ac quaenam fovendae Sanctae Sedis Apostolicae cum eo amicitiae occasiones possint existere (sive ad inferendum sinceriorem Dei cultum in illum ingentem Septentrionis, atque Orientis tractum, sive ad Christianos Principes animandos, ad foedus cum eo sanciendum, vel certe, quod inprimis optandum est ad rem Christianam solidius apud eum statuendam) hoc Commentario, Deo aspirante, exponam. »

66. Possevino (1586), Commentaire I, $\mathrm{f}^{\circ} 31-46 \mathrm{v}^{\circ}$ et Commentaire II, $\mathrm{f}^{\circ} 13-25$.

67. Possevino (1586), Commentaire $\mathrm{I}, \mathrm{f}^{\circ} 33 \mathrm{v}^{\circ}:$ : [...] illud pro certissimo habendum est, per Moscoviam multo minore sumptu atque periculo, quam per omnes alias mundi plagas, patere viam in Asiam, ad Christi Domini fidem propagandam. »

68. La stratégie de conversion de la Russie est développée dans PossEvino (1586), Commentaire I. 
religieux et historiques avec la Russie moscovite des tsars sont très importants ${ }^{69}$. Une fois formés dans les collèges jésuites de Lituanie, ces missionnaires ruthènes pourraient être envoyés en Russie où il leur serait facile d'entrer en contact avec la population locale.

Outre la formation de missionnaires, Possevino recommande la fondation de typographies destinées à l'impression d'ouvrages religieux catholiques en russe afin de mettre fin à l'ignorance « abyssale » des Russes à l'égard du catholicisme et de les aider à se rendre compte de leurs hérésies. Par ailleurs, afin d'attirer les Russes orthodoxes, le jésuite italien suggère au pape de leur promettre de maintenir la liturgie slavonne à laquelle ils sont passionnément attachés, du moins temporairement. Possevino fait preuve d'une certaine flexibilité à propos de la diversité des rites à condition que ces derniers ne contredisent pas les dogmes. Enfin, comme l'entreprise de conversion de la Russie s'avère être une œuvre très difficile «perdifficile negotium » - et longue, Possevino propose dans un premier temps de commencer par les territoires ruthènes orthodoxes de la Pologne-Lituanie. Car contrairement à la Russie où la liberté d'action des missionnaires catholiques serait inévitablement entravée par le pouvoir absolu du tsar, hostile à l'égard de tout prosélytisme catholique, la Pologne-Lituanie est dirigée par un roi dévoué à la cause romaine et de surcroît protecteur des jésuites. La Compagnie de Jésus trouverait dès lors dans ce pays un terrain d'action idéal pour s'appliquer au ralliement de l'Église orthodoxe ruthène. Possevino est en effet convaincu que de la réussite de cette conversion dépendra un succès futur à Moscou ; de fait, étant donné les liens ecclésiastiques anciens entre les évêques ruthènes et leurs collègues russes, ces derniers ne manqueraient pas d'être influencés par un rapprochement de l'Église ruthène avec Rome. Ainsi quinze ans avant l'union de Brest-Litovsk (1596), Possevino a déjà défini de cette façon les fondements de l'Uniatisme ${ }^{70}$.

Contrairement au traité Moscovia, les récits de voyage de Possevino et de Campana sont demeurés longtemps inédits - respectivement jusqu'en 1841 et 1960/1961 - et sont pour cette raison moins connus des historiens. Ces récits, présentés comme des rapports adressés au général des jésuites Claudio Acquaviva, méritent cependant l'intérêt parce que leurs auteurs racontent de manière vivante leur périlleux voyage en Russie en 1581-1582 et décrivent leurs impressions sur ce

69. Du fait de leur appartenance commune à la Russia kiévienne entre le $\mathrm{X}^{\mathrm{e}}$ et le milieu du XIII' siècle.

70. Voir à ce sujet e.a. O. Halecki, From Florence to Brest (1439-1596), Rome - New York, 1958, p. 199-419 ; A. Jobert, De Luther à Mohila. La Pologne dans la crise de la chrétienté 15171648, Paris, Institut d'études slaves, 1974,p. 321-373 (Collection historique de l'Institut d'études slaves, 21) et M. Dmitriev, Brestskaja unija 1596 g. i obščestvenno-političeskaja bor’ba na Ukrajne i v Belorussii. Čast' 1. Brestskaja unija 1596 g. Istoričeskie pričiny (L'union de Brest de 1596 et le conflit politico-social en Ukraine et en Biélorussie. Première partie. L'union de Brest de 1596. Les raisons historiques), Moscou, Indirik, 1996. L'Église uniate ou Église catholique de rite oriental a été fondée en 1596 lors de l'«Union de Brest» [Brest-Litovsk en actuelle Biélorussie]; elle reconnaît l'autorité du pape ainsi que les dogmes catholiques, mais a conservé les rites orthodoxes et le slavon comme langue liturgique. Elle est appelée aussi Église gréco-catholique à partir de 1764 et Église catholique d'Ukraine au Xx ${ }^{\mathrm{e}}$ siècle. 
pays inconnu ${ }^{71}$. En outre, contrairement au récit de Possevino qui se limite uniquement au voyage, celui de Campana apporte une contribution particulièrement intéressante à la connaissance occidentale de la Russie parce que son auteur interrompt, à deux reprises, la narration du voyage pour décrire la religion orthodoxe des Russes $^{72}$. C'est pourquoi je concentrerai mon étude sur ce texte qui n'a guère jusqu'à présent retenu l'attention des chercheurs.

Une étude comparée des descriptions de la religion des Russes dans le récit de Campana et la Moscovia de Possevino écrites à peu près au même moment révèle des similitudes, mais aussi de grandes différences, comme le montre le tableau suivant :

\section{Description de la religion des Russes}

\begin{tabular}{cl}
\hline \multicolumn{1}{c}{ Récit de voyage de Campana } & \multicolumn{1}{c}{ Moscovia de Possevino } \\
\hline \multicolumn{1}{c}{ Origines du christianisme russe } \\
\hline - Ont reçu la foi des Grecs il y a 500 ans & $\begin{array}{l}\text { - Ont reçu la foi des Grecs il y a } 500 \text { ans, } \\
\text { mais diffèrent de ces derniers sur de } \\
\text { nombreux points }\end{array}$ \\
\hline
\end{tabular}

\section{Structures du clergé séculier}

- Métropolites choisis parmi les moines en raison de leur mode de vie rigoureux

- Évêques et archevêques choisis parmi les moines en raison de leur mode de vie rigoureux
- Métropolite autrefois confirmé par le patriarche de Constantinople, maintenant choisi par le tsar et confirmé par deux ou trois évêques

- Évêques choisis parmi les moines en raison de leur mode de vie rigoureux

- Évêques ne visitent pas leurs évêchés, mais les dirigent à travers leurs représentants

- Évêques exercent un contrôle de la moralité des prêtres sous leur juridiction et peuvent leur imposer des amendes

- Prêtres peuvent se marier une fois avant de devenir prêtres. Une fois veufs, ils doivent devenir moines pour pouvoir encore célébrer la messe
- Prêtres veufs deviennent moines afin de pouvoir encore servir la messe ; s'ils se remarient, ils perdent leur statut ecclésiastique

71. Cf. Possevino (1848) p. 392-401 ; CAMPAna (1960/61), p. 14-17, 24-25 et 38-63. Je songe notamment à la description de la traversée par les jésuites des forêts russes sur la route de Starica racontée de manière très vivante par Campana : «Mais alors que les ténèbres avaient déjà partout recouvert le ciel nuageux, nous entendîmes autour de nous le tir d'une bombarde venu de la forêt proche, ensuite le hurlement des ours, l'aboiement des chiens et le glapissement des renards. Nous étions certains que tous ces cris étaient poussés par des voleurs qui se cachaient dans ces forêts. Comme nous étions peu nombreux, nous recommandant à Dieu par la prière, nous passâmes la nuit sans être blessés et sans dormir en montant la garde, en allumant plusieurs feux et en frappant plusieurs endroits avec des branches, comme si nous coupions du bois, afin de leur faire croire que nous étions plus nombreux qu'en réalité » (CAMPANA (1960/ 61), p. 15). 


\section{Description d'une église russe}

- Description de l'intérieur de la cathédrale de Smolensk

- Description de l'iconostase

- Description générale des icônes

- Une information à propos des icônes : la représentation de la nudité du corps humain est interdite

\begin{tabular}{ll}
\hline \multicolumn{1}{c}{ Description d'un office liturgique } \\
\hline - Vêtements du clergé officiant & - \\
- Chants liturgiques & - \\
- Liturgie en russe & - Idem \\
- Pas de sermon & - Pas de sermon ; le peuple écoute la réci- \\
& tation de Vies de saints ou certaines \\
& homélies écrites par les Pères de l'Église \\
- Absence des femmes à la messe, & - Les femmes et les filles nobles vont \\
excepté six à dix fois par an pour recevoir & rarement à la messe, sauf pour recevoir \\
la communion à l'office du matin & l'Eucharistie, généralement à Pâques \\
- Nobles assistent à l'office pendant que & - Idem \\
les gens du peuple travaillent & \\
- Gens impurs tenus de rester à l'extérieur & \\
de l'église & \\
- Ils n'encensent pas l'autel mais les & \\
icônes & \\
- Pas de génuflexion, mais inclinaison de & - Ils se prosternent front contre terre \\
la tête et des épaules plusieurs fois durant & \\
l'office \\
- Prononcent toujours la même prière :
\end{tabular}

\section{Description du monachisme russe}

- Description générale d'un monastère avec son église à deux étages - rez-dechaussée servant de réfectoire et $1{ }^{\text {er }}$ étage étant l'église proprement dite - et les cellules des moines

- Monastères russes nombreux et peuplés

- Importance religieuse du monastère de la Trinité-Saint-Serge
- Monastères russes différents des monastères catholiques avec leurs cellules individuelles

- Idem

- Prêtres et moines font tous partie du même Ordre

- Prononcent toujours la même prière :

«Seigneur, prends pitié » 


\section{Description du monachisme russe}

- Moines objets du respect populaire pour $\quad$ - Idem

leur mode de vie strict

- Mode de vie strict : chasteté, absti-

nence, vivent de pain, de poisson et de sel

- Ignorance des moines qui n'ont aucune

formation, n'achètent pas de livres et ne

s'adonnent pas aux travaux d'écriture

- Idem

- Idem

\section{Comportement religieux des Russes}

- Grande piété des Russes

- Aucune éducation religieuse ; peu de

Russes connaissent le Notre Père

- Peuple se rend peu à l'office car

travaille le dimanche et les jours de fête

- Jeûnent et font pénitence avant de communier

- Nombreuses périodes de jeûne et d'abstinence : se privent de viande, de lait et d'œufs durant les périodes de jeûne ainsi que tous les mercredis et vendredis

- Se signent et se prosternent devant chaque représentation de la croix et les icônes rencontrées

- Présence d'une icône dans chaque maison, devant laquelle tout invité s'incline avant de saluer les habitants

- Vénèrent les saints et leurs reliques

- Culte de saint Nicolas
- Idem

- Ignorance des Russes

- Peuple travaille durant les jours de fête, y compris à Noël et à Pâques, mais non le jour de l'Annonciation

- Observent fidèlement les périodes de jeûne, s'abstenant de manger de la viande et des produits lactés

- Idem

- Idem

- Idem

- Baptisent leurs chevaux et les icônes

\section{Cérémonies et fêtes religieuses des Russes}

- Description de la fête de la Trinité célé-

brée le lundi après la Pentecôte

- Ignorent plusieurs fêtes catholiques ou

les célèbrent à une autre date

- Description de la procession du

dimanche des Rameaux

- Bénédiction des eaux du fleuve deux

fois l'an : le jour de l'Épiphanie et de

l'Assomption de la Vierge

- Cérémonie des funérailles

- Culte des morts : cérémonie du repas

des défunts 


\begin{tabular}{cl}
\hline \multicolumn{1}{c}{ Sacrements de l'Église russe } \\
\hline- & - Baptême des enfants \\
& par triple immersion \\
- & - Extrême-onction \\
- Communion sous les deux espèces & - \\
\hline
\end{tabular}

La lecture du tableau montre que les descriptions de la religion des Russes dans le récit de Campana et la Moscovia de Possevino sont complémentaires. En effet le premier écrit est plus complet pour un certain nombre d'aspects concernant notamment l'intérieur d'une église russe, la description de l'iconostase et des icônes, l'organisation d'un monastère ou encore le déroulement de la liturgie et de certaines fêtes religieuses (fête de la Trinité et dimanche des Rameaux). Le second, quant à lui, fournit des informations à propos du baptême et de l'extrême-onction, deux sacrements de l'Église russe qui n'apparaissent pas dans le récit de Campana. Par ailleurs, Campana concentre son attention quasi uniquement sur la religion des Russes, alors que son collègue analyse également les différents traits du pouvoir absolu du tsar.

Si les deux textes se complètent au niveau de leur contenu, ils n'en comportent pas moins de grandes différences. En effet, contrairement à Possevino qui a écrit sa description de la religion russe et du pouvoir du tsar en tenant compte des écrits de ses prédécesseurs, Campana rédige une description originale de la religion des Russes fondée principalement sur son expérience de témoin oculaire. Cela s'observe notamment dans la description détaillée du cérémonial complexe autour de l'Eucharistie auquel Campana a assisté dans la cathédrale de Smolensk. Sur certains thèmes, Campana est même le premier auteur occidental à apporter des informations précises. Je songe en particulier à l'aménagement intérieur de la cathédrale de Smolensk qu'il a eu l'occasion de contempler durant la liturgie. Il fournit dans ce cadre une description précise de l'iconostase et des icônes ainsi que de leur rôle dans la liturgie orthodoxe russe, comme aucun voyageur occidental en Russie avant lui n'a pu le faire. En choisissant de décrire de manière détaillée la cathédrale de Smolensk, première église russe qu'il a visitée, Campana cherche à donner à son lecteur une impression générale de l'intérieur des églises russes généralement interdites aux non-orthodoxes. Laissons-lui à présent la parole :

C'était une église en pierre fort haute, assez belle à l'intérieur, munie de coupoles à l'extérieur - ces coupoles ressemblaient fort à l'église SainteSophie de Constantinople - s'appuyant sur des piliers carrés, et édifiée en forme de croix ; sur le côté droit se trouvent deux chapelles fermées par des grilles de bois ; il n'y a pas de chœur, comme dans nos églises, pas de bancs et pas d'orgues. La partie de la croix [plan de l'église] située en face de l'entrée de l'église a été fermée par une paroi ; des deux parties séparées par cette paroi, l'une [le sanctuaire] n'est jamais ouverte, sauf lorsque le pain, après avoir été béni à l'intérieur [du sanctuaire] est montré à travers une porte [aux fidèles] avec des prières pour revenir ensuite par une autre porte, appelée la porte du roi ; personne n'ose franchir la porte royale, excepté le clerc qui demeure seul à 
l'intérieur [du sanctuaire] jusqu'à ce que le pain soit consacré et la communion accomplie. Le dessus des portes et l'ensemble de la paroi érigée sur toute la largeur de l'église sont quasi totalement recouverts d'icônes sacrées ; on trouve des images de ce genre non seulement dans cette cathédrale, mais aussi dans toutes les églises en Russie, y compris les petites, et toutes ces images sont peintes de la même façon sur des panneaux de bois avec du minium, de l'or et de la couleur. Dans une très petite église, j'ai compté plus de deux cents tableaux de ce genre, placés suivant un ordre et une certaine proportion, où celles qui étaient plus basses étaient aussi plus petites. Beaucoup de ces images représentent la Passion du Christ, la Mère de Dieu à l'Enfant, Jean-Baptiste, les Anges et les Apôtres. Saint Nicolas, l'évêque de Myre, est très célèbre chez eux, parce que l'image de ce dernier qu'ils ont dans la ville de Možajsk a produit et produit encore, disent-ils, des miracles. C'est pourquoi ils peignent souvent avec la plus grande déférence des images de saint Nicolas en habit épiscopal sur un tableau de grande taille au milieu; autour de ce tableau, ils peignent divers tableaux de petite taille [appelés klejma en russe] sur l'un desquels, au dessus de la tête de saint Nicolas, ils peignent l'image de la Très Sainte Vierge à l'Enfant ${ }^{73}$.

Un autre exemple de la qualité du témoignage de Campana s'observe dans sa description physique d'un monastère russe parmi tous ceux qu'il a visités au cours de son séjour en Russie. Ici encore son témoignage est précieux pour ses lecteurs occidentaux dans la mesure où les monastères étaient, tout comme les églises, des lieux sacrés fermés aux étrangers « impies » :

Nous sommes entrés dans un monastère où nous avons tout vu; ce monastère avait deux églises. Le rez-de-chaussée de l'église - les églises elles-mêmes sont non seulement toutes semblables mais se trouvent aussi au premier étage servait de réfectoire avec une cuisine sur le côté droit. Les tables, comme chez nos religieux, sont étroites, longues et placées le long des murs, contre lesquels on prend place. Toutes les églises en bois ou en pierre - ces dernières étant très rares - ont été édifiées en forme de croix pour reproduire l'image matérielle de la Très Sainte-Trinité tandis que les trois coupoles sont surmontées de croix de

73. «Erat templum lapideum praealtum sic satis pulchrum intus forisque turritum; turres ferme sunt admodum templi S. Sophiae Constantinopoli, quadrangulis columnis innitens ac ferme crucis in formam aedificatum; in dextro latere duo sacella cancellis ligneis munita habent ; ibi chorus nullus, ut in nostris, sedilia nulla, organa nulla. Pars crucis quæ respondet ingressui templi clausa est, erecto pariete crucis, relictis duabus partibus, quarum una nunquam aperitur nisi cum panis primo intus benedictus cum supplicatione, foris effertur per aliam portam, ut inferatur per illam quæ dicitur porta regis, quam nullus alius ingredi audet preter clerum tum temporis, qui etiam solus intus manet, donec consecratus fiat et communio consumatur. Supra igitur portas illas imo per totum illum parietem, in latitudinem templi protensum fere omnia sunt sacris iconibus contecta ; id quod non modo est in illa cathedrali, sed in omnibus per Moschoviam quantumvis parvis ecclesiis omnesque huiusmodi imagines in tabulis sunt minio auro coloreque depictae. In perparva ecclesia numeravi huiusmodi tabulas ultra ducentas, ordine tamen ac proportione quadam collocatas, ut quo inferiores, eo etiam sint minores. In his Christi Passi multae, Deiparae cum infantulo, Ioannis Baptistae, Angelorum Apostolorum ; celeberrimus est apud illos S. Nicolaus, Mirrae episcopus, quod quaedam imago eius quam in civitate Mosaiski habent, multa ediderit edatque - ut dicunt miracula, et ideo illius imagines quandoque honoreficentissime pingunt in media tabula forma pregrandi habitu episcopali circum vero illam pingunt varias illas minore forma, in quibus tamen B.mae Virginis imaginem supra caput illius reponunt cum filio. » (CAMPANA, 1960/61, p. 18). 
fer. [...] Ils [les moines] ont des cellules dispersées sur un grand espace et séparées les unes des autres. Ces cellules comptent deux ou trois pièces, comme chez les chartreux, mais qui sont sales, couvertes de suie, sombres et dépourvues de lit, de table, de coffre et de banc, excepté ces bancs qui sont fixés autour du poêle et que les moines utilisent comme table, comme siège, comme lit ainsi que pour d'autres usages ${ }^{74}$.

Si le témoignage personnel occupe une grande part de la description de Campana, ce dernier n'a cependant pas pu tout observer en un séjour qui a été, rappelons-le, en réalité plus bref que celui de ses compagnons. Le récit de Campana décrit certaines traditions religieuses russes d'après des informations qu'il tient de tierces personnes. Je songe en particulier à la procession du dimanche des Rameaux ou encore à la fête à la Trinité célébrée le lundi après la Pentecôte, cérémonies auxquelles il n'a pu assister n'étant pas en Russie à ce moment-là75. Pourquoi Campana s'est-il intéressé à ces fêtes et non à celle de Pâques pourtant si importante pour les orthodoxes russes reste un mystère. Par ailleurs, il n'est malheureusement pas possible de connaître l'origine des informations recueillies par Campana, car ce dernier ne cite jamais ses sources orales, se contentant plutôt de formules vagues telles que « il m'a été relaté ».

Avant de passer à l'étude de la diffusion des écrits de Possevino et de Campana, il convient de procéder à une brève analyse critique de leur contenu. Que les deux jésuites consacrent une partie non négligeable de leurs écrits à la religion des Russes s'explique dans le cadre des instructions pontificales. Il importe de s'interroger sur les raisons qui ont motivé la sélection de certains aspects de la religion orthodoxe au détriment d'autres. À la lecture de la Moscovia de Possevino et du récit de voyage de Campana, on constate, d'une part, que les deux jésuites s'intéressent, dans le contexte de la Contre-Réforme, aux aspects qui rapprochent les orthodoxes des catholiques par opposition aux protestants : le monachisme, le culte des saints, le culte des images ou la hiérarchie ecclésiastique. Ces aspects militeraient en faveur d'un rapprochement entre les Églises romaine et russe. D'autre part, contrairement à certains de leurs prédécesseurs, tels Fabri, Pighius ou Cobenzl, les deux jésuites font preuve d'une grande lucidité quant aux obstacles qui s'opposent à une telle Union. Ces obstacles sont notamment le refus de reconnaître la primauté du pape et les préjugés anti-latins solidement ancrés au sein de la population russe, inculte et isolée du

74. «Illud etiam ingressi perlustravimus omnia; ecclesiolas duas habebat; vestibulum ecclesiae - sunt enim omnes non solo aequales, sed ad primam contignationem erectae triclinium erat, cum coquina ad latus dextrum mensae, ut apud religiosos nostros sunt strictae, oblongae et circumquaque positae, quibus ad parietem tantum accumbitur. Ecclesiae omnes sive ligneae sive lapidae - quae perpaucae sunt - in modum crucis edificatae sunt, ut et Sanctissimae Trinitatis speciem quandam corpoream referant trifariam tectorum consensione consurgunt ferreas cruces. (...) Cubicula habent per aream magnam extensa et ab invicem separata bina vel terna simul ad morem Carthusianorum, sed sordida, fuliginosa, obscura ; absque lecto vel mensa vel cista vel scamno, exceptis solis iis, que circa hypocaustum sunt affixa, quae illis serviunt pro mensa, sedili, lectica, cubili et omnibus aliis usibus huiusmodi. » (CAMPANA, 1960/61, p. 26).

75. CAMPana, 1960/61, p. 32. 
reste de l'Occident par le pouvoir despotique du tsar tout-puissant. Dans leurs écrits, Campana et Possevino essaient d'évaluer à leur juste mesure les chances réelles de succès des projets d'Union romains afin de mettre fin, une fois pour toutes, aux illusions dont la Curie est régulièrement bercée.

Si Possevino et Campana se prévalent d'une expérience de terrain et des réelles opportunités qu'ils ont eues durant leur séjour pour découvrir la Russie et en particulier ses traditions religieuses, il n'empêche que leurs écrits ne sont pas exempts d'imperfections. On peut notamment évoquer une certaine attitude tendancieuse de la part de Possevino dans sa façon de décrire le clergé russe ou lorsqu'il compare les Russes aux Scythes et aux Tatars sans donner de justification et réduit le portrait d'Ivan le Terrible à celui d'un despote sanguinaire. Il est vrai que ces deux images sont devenues des lieux communs de la représentation du monde russe dans l'Occident de la Renaissance ${ }^{76}$. Outre ces traits tendancieux, on observe également des erreurs dans les descriptions concernant la Russie. Pour ne reprendre qu'un seul exemple, Possevino présente les archimandrites et les higoumènes comme des fonctionnaires travaillant pour le compte de l'évêque alors qu'ils sont avant tout respectivement les supérieurs des grands monastères et des monastères moins importants ${ }^{77}$. Ces erreurs n'entachent cependant pas la qualité du témoignage de Possevino et de Campana.

\section{La réception des premiers écrits jésuites sur la Russie dans le monde lettré occidental}

Dès sa parution en 1586, la Moscovia de Possevino connaît une grande renommée, qui s'explique, selon moi, moins par son contenu centré autour du problème de l'union des Églises que par la réputation du jésuite italien qui s'est rendu célèbre en parvenant à mettre fin à vingt-trois ans de Guerre de Livonie (1558-1582). Le succès de la Moscovia est attesté au cours de la dernière décennie du XVIe siècle par trois rééditions de la version originale (à Anvers en 1587 et à Cologne en 1587 et $1595)$ et par une traduction en italien réalisée par Giovanni Battista Possevino, neveu du jésuite italien, et publiée à Ferrare en 1592 et à Mantoue en 1596.

Un autre élément indicateur de la réception de la Moscovia dans le monde lettré de la fin du XVI ${ }^{\mathrm{e}}$ siècle réside dans les emprunts qui lui ont été faits par d'autres auteurs soucieux de décrire la Russie sans s'y être personnellement rendus. Quoique le nombre d'emprunts au traité de Possevino ne rivalise pas avec le succès de Herberstein, l'auteur le plus abondamment copié à propos de la Russie durant la Renaissance, on trouve néanmoins différents emprunts à la Moscovia chez au moins deux auteurs de la fin du XVIe siècle : le théologien allemand David Chytræus

76. Voir à ce sujet notamment le livre de M. T. Poe, A People born to slavery : Russia in early modern European ethnography, 1476-1748, Ithaca - Londres, Cornell University Press, 2000.

77. Possevino (1586), Commentaire II, $\mathrm{f}^{\circ} 2$. 
et le théologien, diplomate et penseur politique italien Giovanni Botero ${ }^{78}$. Les emprunts de Chytræus à la Moscovia sont nombreux et divers dans sa chronique Chronicon Saxoniæ et vicini orbis arctoi publiée en 1590 à Rostock chez Stephan Myliander ${ }^{79}$; ils concernent notamment l'organisation du clergé russe, le droit de propriété absolu du tsar sur la Russie, les conseillers d'Ivan le Terrible et l'absence d'universités et d'académies en Russie ${ }^{80}$. Pour sa part, Botero décrit à trois reprises la Russie dans son traité de géographie politique Le relationi universali composé entre 1591 et 1596 et édité pour la première fois dans son intégralité en 1595-1596 à Bergame chez Comino Ventura ${ }^{81}$. Parmi les différents ouvrages auxquels Botero recourt pour décrire le pays des tsars, on trouve la Moscovia de Possevino qu'il emploie pour présenter entre autres les richesses de la Russie dans la deuxième partie des Relationi universali consacrée aux principaux souverains du monde de l'époque ${ }^{82}$.

Bien qu'ils soient restés longtemps inédits, les récits de Possevino et de Campana ont néanmoins connu une certaine diffusion à travers un texte intitulé Missio Muscovitica. L'auteur anonyme de ce texte n'a, pour sa part, laissé apparaître dans son récit aucune information sur sa présence éventuelle dans les lieux qu'il décrit ni sur sa personne. Toutefois je pense qu'il était certainement un membre de la Compagnie de Jésus, car il a publié son texte dans les Annuæ litteræ Societatis Iesu Anni M.D.LXXXII ad Patres et Fratres ejusdem Societatis, un

78. David Chytræus $(* 1531-\uparrow 1600)$ est un théologien protestant formé à Tübingen et à Wittenberg. Devenu professeur à l'université de Rostock, il a laissé de nombreux ouvrages religieux et d'histoire. Au sujet de Chytræus et de son intérêt pour la Russie, voir W. Engels, « Die Wiederentdeckung und erste Beschreibung der östlich-orthodoxen Kirche in Deutschland durch David Chytræus (1569) », Kyrios Vierteljahresschrift für Kirchen- und Geistesgeschichte Osteuropas, 4,1939/40, p. 262-285. Giovanni Botero (*1544-†1617) a commencé sa carrière chez les jésuites, qu'il quitte en 1580. Par la suite il se met au service de saint Charles Borromée, puis du duc de Savoie Charles-Emmanuel I I r. Il devient précepteur des fils de ce dernier tout en continuant de participer à des missions diplomatiques à l'étranger. Botero est l'auteur de nombreux ouvrages de géographie politique. Au sujet de la vie et de l'œuvre de Giovanni Botero, voir e.a. A. E. Baldini, ed, Botero e la 'Ragion di Stato'. Atti del convegno in memoria di Luigi Firpo (Torino 8-10 marzo 1990), Florence, Leo S. Olschki, 1992 (Fondazione Luigi Firpo Centro di Studi sul pensiero politico, studi e testi, 1). Pour une brève analyse des informations sur la Russie et la Ruthénie dans le traité de Botero, voir G. D’Amato, Resoconti degli Italiani sulla Moscovia fine $X V$-XVI secolo. Compendio storico-bibliografico. Seconda edizione con correzioni ed aggiunte, Moscou, Russkoe slovo, 1995, p. 129-131.

79. Je me référerai à l'édition de 1599 imprimée à Leipzig sous le titre Saxonia ab Anno Christi 1500 usque ad MDXCIX. Recognita et aliquot annorum accessione et aliis Historiis aucta [cité infra CHYTRæus (1599) - Rome, Biblioteca Vaticana, Mai XI.H.IX. 19]. Le théologien protestant et le jésuite italien se connaissent déjà auparavant par leurs écrits respectifs. Possevino a en effet mené pendant deux ans (1584-1586) une polémique religieuse avec Chytræus, grand zélateur du luthéranisme en Europe du Nord où le père jésuite cherchait à promouvoir la reconquête catholique. Voir à ce sujet W. Engels, op. cit., p. 283-285.

80. Chytræus (1599), p. $23=$ Possevino (1586), f $\mathrm{f}^{\circ} 1-1 \mathrm{v}^{\circ}, 2,5 \mathrm{v}^{\circ}, 10$ et 12.

81. Titre complet : Le relationi universali di Giovanni Botero Benese, in tre parti e cinque volumi divise, con tavole di geografia \& indici copiosi \& particolari a ciascuno di loro, et in questa nova editione dal proprio autore accresciute \& megliorate d'assai, Bergame, Comino Ventura, 6 vol. Je me référerai à l'édition de 1595-96, imprimée à Vicence, qui présente le traité de Botero dans son intégralité [cité infra Botero (1595-96) - Londres, British Library, n C. 68. B. 14].

82. BOTERo (1595-96), II, Lb.I, fo $179=$ POSSEVINO (1586), $\mathrm{f}^{\circ} 11-11 \mathrm{v}^{\circ}$. 
bulletin destiné à l'usage exclusif des jésuites ${ }^{83}$. Publiée en 1584 à Rome, c'est-àdire à une époque où Possevino et Campana séjournaient encore en Pologne après la fin de leur mission chez Ivan le Terrible, la Missio Muscovitica se présente comme une compilation fusionnant les récits de voyage des deux jésuites italiens adressés à Claudio Acquaviva. L'auteur anonyme a divisé son texte en deux parties : la première est consacrée au récit de l'ambassade pontificale en Russie, tandis que la deuxième présente une description synthétique de ce pays, en particulier de la religion orthodoxe pratiquée par les sujets du tsar (fêtes de la Trinité et des Rameaux, culte des morts, vénération des icônes, périodes de jeûne, monachisme). Jusqu'ici les historiens avaient affirmé que la première partie du récit de l'auteur anonyme était une compilation du récit de voyage de Possevino, tandis que la seconde partie était une compilation du récit de voyage de Campana ${ }^{84}$. Ma lecture comparée des trois textes révèle qu'une telle affirmation est partiellement erronée : la première partie du récit de l'auteur anonyme ne s'appuie pas uniquement sur le récit de Possevino, mais se présente comme une compilation des deux récits de voyage de Possevino et de Campana. L'auteur anonyme a utilisé le récit de Possevino pour présenter le début du voyage et surtout le séjour à Moscou durant l'hiver 1582 que Campana n'a pas connu puisqu'il était déjà reparti en Pologne au moment où Possevino a été reçu au Kremlin par Ivan le Terrible. Le récit de Campana a, quant à lui, servi à décrire le séjour des jésuites à Starica, probablement parce qu'il est plus complet que celui de Possevino. En revanche, conformément à l'opinion reçue, la seconde partie est bien, excepté quelques informations, essentiellement inspirée du récit de Campana dont l'auteur anonyme a regroupé les descriptions éparses pour constituer un seul tableau de la Russie et en particulier de la religion orthodoxe pratiquée par ses habitants ${ }^{85}$.

Un dernier point a été mal apprécié par les historiens qui ont étudié la Missio Muscovitica. Ils ont affirmé que ce texte est resté inconnu du public cultivé en dehors des cercles de la Compagnie de Jésus jusqu'à ce qu'il soit publié en 1882 par le père jésuite autrichien Paul Pierling ${ }^{86}$. Or la lecture parallèle des descriptions de la Russie composées durant la Renaissance m'a permis de découvrir que le récit du compilateur anonyme a servi à la fin du XVI ${ }^{\mathrm{e}}$ siècle de source de travail à Giovanni

83. Pour une histoire de ce bulletin, voir J. J. Santich (O.S.B.), op. cit., p. 15-30.

84. Cf. L. N. Godovikova, ed, op. cit., p. 89 ; H. F. Graham, ed., « The Missio Muscovitica », art. cit., p. 447 ; L. N. Godovikova, V. L. Janin, eds., op. cit., p. 252.

85. La lecture comparée aboutit au résultat suivant pour la première partie : ANONYME (1882), p. 8-10 = POSSEVINO (1848), p. 391-392 ; ANONYME, p. 11-25 = CAMPANA (1960/61) p. 14-16, 25, 39, 40-44 ; AnONyme, p. 25-33 = CAMPAnA, p. 44-48 ; AnONyme, p. 33-44 = CAmpanA, p. 50-58; ANONYMe, p. 44-59= Possevino, p. 394-403. La lecture comparée aboutit au résultat suivant pour la seconde partie : ANONYME, p. 59-60 = CAMPANA, p. 24 ; ANONYME, p. 62 = CAMPANA, p. 62 ; ANONYME, p. 63-66 = CAMPANA, p. 21, 38-39, 48-49; ANONYME, p. 67-71 = CAMPANA, p. 20-21, 32, 46-47, 51-52 ; ANONYME, p. 71-73 = CAMPANA, p. 30-31 ; ANONYME, p. 72-74 = CAMPANA, p. 18, 28-29, 35, 36 ; ANONYME, p. 74-80 = CAMPANA, p. 3134 ; AnONYME, p. 78-79= CAMPANA, p. 21 ; ANONYME, p. 80-86= CAMPANA, p. 18, 26-28, 32.

86. Cf. L. N. Godovikova, ed., op. cit., p. 89 ; H. F. Graham, ed., « The Missio Muscovitica », art. cit., p. 447 ; L. N. Godovikova, V. L. Janin, eds., op. cit., p. 252. 
Botero déjà évoqué plus haut ${ }^{87}$. Avant de se lancer dans la rédaction des ouvrages de pensée politique qui l'ont rendu célèbre, Botero a vécu pendant plus de vingt ans parmi les jésuites (1559-1580), dont il a d'abord été l'élève avant de devenir ensuite professeur de rhétorique dans plusieurs de leurs collèges en France et en Italie. Bien qu'il les eût quittés depuis quelques années (1580) au moment de la parution de la Missio Muscovitica (1584), il a certainement connu l'existence de ce récit, probablement grâce aux relations qu'il avait dû conserver au sein de la Compagnie. Par la suite, il l'a utilisé pour la composition de son traité de géographie politique universelle, les Relationi Universali. Ainsi dans la première partie des Relationi Universali - elles en comptent cinq au total - consacrée à la description générale des différents pays du monde (Rome, 1591), on trouve déjà quelques renseignements sur la société russe (cérémonial pompeux de la cour, servilité des sujets du tsar, ignorance généralisée, vénération des icônes, etc.) qui peuvent avoir été inspirés de la lecture du texte du compilateur anonyme ${ }^{88}$. Mais c'est surtout dans la troisième partie de ce traité, consacrée aux différentes religions du monde (Rome, 1595), que l'on trouve reproduite dans la rubrique de la Russie la description de la religion des Russes du compilateur anonyme présentée dans le même ordre que ce dernier sans que le texte soit toutefois copié mot à mot ${ }^{89}$. Si l'emprunt est dans le cas présent indéniable, Botero ne mentionne pourtant jamais la Missio Muscovitica parmi ses sources, mais se contente de citer à l'occasion les noms de Herberstein et de Possevino ${ }^{90}$. Ce silence explique probablement pourquoi les historiens ont ignoré jusqu'à aujourd'hui l'influence pourtant bien réelle que ce texte a exercée sur le traité de Botero et la diffusion qu'il a connue indirectement à la fin du XVIe et au long du XVII siècle par le biais des nombreuses éditions et traductions du traité Relationi Universali ${ }^{91}$.

\section{Conclusion}

Bien qu'entrés tardivement sur la scène des relations diplomatiques entre la Russie moscovite et l'Occident, les jésuites occupent à la fin du Xvie siècle une place importante dans la production de descriptions du pays des tsars, lesquelles se situent dans la tradition des célèbres traités occidentaux de chorographie de Giovio et de Herberstein et des récits de voyage anglais de la seconde moitié du XvI siècle. Les descriptions de la Russie écrites par Possevino et son collègue Campana appor-

87. Au sujet de la relation entre Botero et le récit de compilateur anonyme, voir S. Mund, « Iezuitskie rasskazy », art. cit., p. 352-355.

88. Botero (1595-96), I, Lb.I, fo 58 = ANONYMe (1882), p. 62 ; Botero, I, Lb.I, fo $59=$ ANONYME, p. 71.

89. BOTERO (1595-96), III, Lb.I, f 51-52 = ANONYME (1882), p. 70-86.

90. BOTERo (1595-96), I, Lb.I, f ${ }^{\circ} 58 \mathrm{v}^{\circ}$ et II, Lb.I, fo 177.

91. Traité publié dix-neuf fois au XvI siècle à Rome, à Ferrare, à Bergame, à Venise, à Vicence, à Brescia, à Helmstedt, à Cologne et à Valladolid. Traduit en latin à Cologne (1596), en espagnol à Valladolid (1599) et en allemand à Cologne (1599). 
tent un éclairage particulier sur les dernières années du règne agité d'Ivan le Terrible que les deux jésuites ont eu personnellement l'occasion de côtoyer en 1581-1582; Possevino est par exemple un des premiers auteurs occidentaux à évoquer les circonstances de la mort du tsarévitch Ivan, héritier d'Ivan IV, qui a eu lieu quelques semaines avant son arrivée à Moscou. Elles contribuent, surtout dans le cas du récit de Campana, à un renouvellement des connaissances occidentales sur la religion russe depuis les traités de Fabri, de Giovio et de Herberstein. En effet, elles contiennent plusieurs informations de première main dans la mesure où les jésuites ont pu visiter des lieux habituellement fermés aux étrangers tels que les églises et les monastères. Cependant la qualité indéniable de leur témoignage n'empêche pas la présence d'erreurs ainsi qu'une certaine vision tendancieuse de la part des deux jésuites italiens. L'ensemble des écrits jésuites et apparentés consacrés à la Russie à la fin du XVI siècle montre ainsi clairement que, dans sa campagne de reconquête catholique de l'Europe, la «Milice du pape »n'a pas oublié le pays des tsars.

Université de Cambridge

Wolfson College

Université libre de Bruxelles

mundstephane@yahoo.fr 